\title{
Association behavior between sand tiger sharks and round scad is driven by mesopredators
}

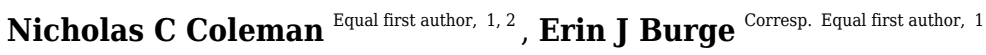 \\ ${ }^{1}$ Department of Marine Science, Coastal Carolina University, Conway, South Carolina, United States \\ 2 Chesapeake Biological Laboratory, University of Maryland Center for Environmental Sciences, Solomons, Maryland, United States \\ Corresponding Author: Erin J Burge \\ Email address: eburge@coastal.edu
}

In marine systems, behaviorally-mediated indirect interactions between prey, mesopredators, and higher trophic-level, large predators are less commonly investigated than other ecologic interactions, likely because of inherent difficulties associated with making observations. Underwater videos ( $n=216)$ from SharkCam, a camera installation sited beneath Frying Pan Tower, a decommissioned light house and platform, on a natural, hard bottom site approximately $50 \mathrm{~km}$ off Cape Fear, North Carolina, were used to investigate association behavior of round scad Decapterus punctatus around sand tiger sharks Carcharias taurus. Videos containing sand tiger sharks were analyzed for the simultaneous presence of round scad, and six species of scad mesopredators, with scadshark interactions assigned to one of three categories of association: no visible interaction, loosely associated, or tightly associated. The likelihood of scad being loosely or tightly associated with sharks was significantly higher in the presence of scad mesopredators, suggesting that sharks provide a predation refuge for scad. This behaviorally-mediated indirect interaction has important implications for trophic energy transfer and mesopredator control on hard bottoms, as scad are one of the most abundant planktivorous fish on hard bottoms in the western Atlantic Ocean. Although we were not able to provide statistical evidence that sand tiger sharks also benefit from this association behavior, we have clear video evidence that round scad association conceals and attracts mesopredators, enhancing predation opportunities for sand tiger sharks. These interactions potentially yield additional trophic consequences to this unique association and highlight the value of exploring behaviorally-mediated interactions in marine communities. 


\section{Association behavior between sand tiger sharks and round 2 scad is driven by mesopredators}

3 Nicholas C. Coleman ${ }^{1,2, *}$ and Erin J. Burge ${ }^{1, *}$

$4{ }^{1}$ Department of Marine Science, Coastal Carolina University, Conway, South Carolina 29528

$6 \quad{ }^{2}$ Present address: Chesapeake Biological Laboratory, University of Maryland Center for

7 Environmental Sciences, Solomons, Maryland 20688

8

$9 \quad$ *Equal first authors

10

11

12 Corresponding Author:

13 Erin J. Burge ${ }^{1}$

14 Coastal Carolina University, Department of Marine Science, 107 Chanticleer Drive East,

15 Conway, South Carolina, 29528, USA

16 Email address: eburge@coastal.edu 


\section{Abstract}

18 In marine systems, behaviorally-mediated indirect interactions between prey, mesopredators, and

19 higher trophic-level, large predators are less commonly investigated than other ecologic

20 interactions, likely because of inherent difficulties associated with making observations.

21 Underwater videos $(\mathrm{n}=216)$ from SharkCam, a camera installation sited beneath Frying Pan

22 Tower, a decommissioned light house and platform, on a natural, hard bottom site approximately

$2350 \mathrm{~km}$ off Cape Fear, North Carolina, were used to investigate association behavior of round

24 scad Decapterus punctatus around sand tiger sharks Carcharias taurus. Videos containing sand

25 tiger sharks were analyzed for the simultaneous presence of round scad, and six species of scad

26 mesopredators, with scad-shark interactions assigned to one of three categories of association: no

27 visible interaction, loosely associated, or tightly associated. The likelihood of scad being loosely

28 or tightly associated with sharks was significantly higher in the presence of scad mesopredators,

29 suggesting that sharks provide a predation refuge for scad. This behaviorally-mediated indirect

30 interaction has important implications for trophic energy transfer and mesopredator control on

31 hard bottoms, as scad are one of the most abundant planktivorous fish on hard bottoms in the

32 western Atlantic Ocean. Although we were not able to provide statistical evidence that sand tiger

33 sharks also benefit from this association behavior, we have clear video evidence that round scad

34 association conceals and attracts mesopredators, enhancing predation opportunities for sand tiger

35 sharks. These interactions potentially yield additional trophic consequences to this unique

36 association and highlight the value of exploring behaviorally-mediated interactions in marine

37 communities.

39 Introduction 
Multispecies interactions highlight the underlying interdependency between organisms that

41

42

43

44

exist in all communities (Hutchinson, 1959; Paine, 1984; Beard \& Dess, 1988). These

interactions are often categorized as direct, between two species, or indirect, where the interaction between two species ultimately affects a third species (Wootton, 1993). Behaviorallymediated indirect interactions (BMIIs) are a further classification of trait-mediated indirect interactions (TMIIs) that are regulated by changes in a species' behavior (Dill, Heithaus \& Walters, 2003). Both direct and indirect interactions produce changes in a species' density or behavior and are useful in understanding food webs and trophic exchanges. Indeed, indirect affects alter the risk landscapes of prey, including mesopredators which are prey species for larger carnivores (Ritchie \& Johnson, 2009), especially in aquatic ecosystems (Preisser, Bolnick \& Benard, 2005; Heupel et al., 2014), and can initiate trophic cascades (Schmitz, Krivan \& Ovadia, 2004; Creel \& Christianson, 2008). Competitor facilitation has been used in the context of BMIIs when the presence of one species of predator causes a change in the behavior of a prey species that makes that prey species more accessible for a second species of predator (Dill, Heithaus \& Walters, 2003). For example, some marine, demersal mesopredatory fishes access pelagic prey that are driven towards the seafloor by pelagic mesopredators, enhancing feeding opportunities (Auster et al., 2009, 2013; Campanella et al., 2019). Despite their importance, BMIIs are less commonly investigated than other ecologic interactions because of the difficulty attributed to quantifying changes in behavior, especially within marine habitats.

\section{Underwater observations}

Underwater videography using stationary cameras is an efficacious method to conduct in-situ marine observations, including surveying marine fish assemblages for species richness and abundance, and behavioral observations (reviewed in Mallet \& Pelletier, 2014). For example, 
63 video has revealed that hard bottom habitat near Frying Pan Tower, $50 \mathrm{~km}$ offshore of Cape

64 Fear, North Carolina, supports a diverse assemblage of both temperate and tropical reef fish

65 species that fluctuates seasonally (Burge et al., 2012; Burge, O'Brien \& jon-newbie, 2020). With

66 few exceptions, the use of underwater video to assess multispecies behavior that includes large

67 and highly mobile predators, is much more limited (but see Davis et al., 1999; Dunbrack \&

68 Zielinski, 2003; Barker, Peddemors \& Williamson, 2011; Bond et al., 2012; Kanno et al., 2019;

69 Brown et al., 2020), despite evidence that video may be an advantageous survey method

70 (McCauley et al., 2012).

71 Once recorded, videos can be reviewed multiple times to optimize the amount of data

72 collected from a single event, and can potentially increase recognition of behaviors that would

73 otherwise be difficult to assess during SCUBA diving observations, which are depth and time

74 limited, especially in multispecies interactions where participants may have different reactions to

75 the presence of observers. Potential bias associated with SCUBA surveys can be introduced as

76 fish react to the presence of divers, sometimes for long periods post-survey (Emslie et al., 2018),

77 and this effect has been observed to be species specific (Cole, 1994; Kulbicki, 1998; Burge et al.,

78 2012; Lindfield et al., 2014). For example, sand tiger sharks display increased respiration and

79 movement in the presence of SCUBA divers (Barker, Peddemors \& Williamson, 2011),

80 providing evidence that underwater stationary videography may be a better alternative to observe

81 the behavior of this species.

82 Sand tiger sharks (STs)

83 Sand tiger sharks, Carcharias taurus Rafinesque, 1810, are large (to $>4 \mathrm{~m}$ ), heavy-bodied

84 lamniforms found in coastal and continental shelf waters of warm-temperate and tropical seas

85 worldwide. The diet of $C$. taurus is diverse and dominated by bony fishes and other 
86 elasmobranchs (Gelsleichter, Musick \& Nichols, 1999). Individuals and aggregations occur

87 especially in coastal areas of Australia (where they are known locally as grey nurse sharks), the east coast of South Africa (raggedtooth sharks), and the east coast of the United States (sand tiger sharks). Sand tiger shark aggregations are associated with migratory behavior, feeding, and reproduction (Compagno, 2001), and complex social networks and behaviors are described in this species (Haulsee et al., 2016a). Year-to-year site fidelity on shipwrecks and other artificial structures has been reported in North Carolina (Paxton et al., 2019) and individuals tagged in Delaware Bay undergo long-distance migrations to overwinter in continental shelf waters of North Carolina (Teter et al., 2015) and return to Delaware Bay predictably (Haulsee et al., 2016b). Additionally, sand tiger sharks are one of the few large-bodied sharks commonly housed in captivity (Govender, Kistnasamy \& Van Der Elst, 1991; Gordon, 1993; Smale et al., 2012). with some regional populations considered endangered or critically endangered (Cavanagh et al., 2003; Chiaramonte, Domingo \& Soto, 2007). Assessment of C. taurus in the northwestern Atlantic has suggested this population declined precipitously since the 1970s from overfishing in the 1980s to the mid-1990s (Musick, Branstetter \& Colvocoresses, 1993; Musick et al., 2000), but analyses of multiple datasets now suggest only low to moderate declines in abundance (0.2$6.2 \%$ ) (Carlson et al., 2009), in conflict with previous reports. More recent data suggest that the northwestern Atlantic population may be stabilized (Frazier, Paramore \& Rootes-Murdy, 2019; Latour \& Gartland, 2020). Regardless, conservative management is recommended due to the 106 very low productivity for this species (Goldman, Branstetter \& Musick, 2006; Carlson et al., 107 2009). Harvest of sand tigers is currently prohibited in the United States under Highly Migratory 
108 Species regulations and Habitat Area of Particular Concern designations are under further

109 consideration (NOAA Fisheries, 2019)

110 Round scad $(R S)$

111 Round scad, Decapterus punctatus (Cuvier, 1829), are small-bodied ( $<300 \mathrm{~mm}$ ) carangids

112 found in the western Atlantic Ocean southward from Nova Scotia, at Bermuda, and in the Gulf of

113 Mexico, Caribbean Sea, and along continental shores of South America to Rio de Janiero

114 (Naughton, Saloman \& Vaught, 1986). In the South Atlantic Bight (SAB), round scad (typically

$11560-170 \mathrm{~mm}$ ) are abundant in continental shelf waters in summer and fall, and move to hard

116 bottoms in deeper, warmer areas of the mid- and outer shelf in winter (Hales Jr., 1987).

117 Throughout their range, adult round scad are diurnal zooplankton specialists with the diet

118 dominated by pelagic species and life stages (for meroplankton), as opposed to demersal 119 plankton (Hales Jr., 1987; Donaldson \& Clavijo, 1994).

120 Round scad are very frequently reported as stomach contents of pelagic and demersal 121 piscivores (Matheson, Huntsman \& Manooch, 1986; Naughton, Saloman \& Vaught, 1986), and 122 are often the most abundant species on FADs (Rountree, 1990), wrecks (Lindquist \& Pietrafesa, 123 1989), and natural live bottoms (Parker, Chester \& Nelson, 1994; Kendall, Bauer \& Jeffrey, 124 2009; Burge et al., 2012) in portions of the SAB. Round scad schooling behaviors around 125 artificial structures (Rountree, 1989, 1990; Lindquist \& Pietrafesa, 1989; Rountree \& Sedberry, 126 1991), while feeding (Rountree \& Sedberry, 1991), and in response to their predators (Auster et 127 al., 2009, 2013; Campanella et al., 2019) suggest an affinity for physical objects which can 128 include larger fishes and elasmobranchs (Fuller \& Parsons, 2019).

129 Mesopredators (MPs) 
A diverse assemblage of pelagic and demersal piscivorous mesopredatory fishes inhabit hard 131 bottom habitats of the SAB (Chester et al., 1984; Sedberry \& Van Dolah, 1984; Kendall, Bauer \& Jeffrey, 2009; Burge et al., 2012; Burge, O’Brien \& jon-newbie, 2020). Pelagic mesopredators include medium to large-sized jacks (e.g.: greater amberjack Seriola dumerili (Risso, 1810),

134 almaco jack Seriola rivoliana Valenciennes in Cuvier and Valenciennes, 1833, blue runner 135 Caranx crysos (Mitchill, 1815), crevalle jack Caranx hippos (Linnaeus, 1766)) and scombrids 136 (e.g.: little tunny Euthynnus alletteratus (Rafinesque, 1810), and Atlantic bonito Sarda sarda 137 (Bloch, 1793)). All are reported to prey on round scad or similar small fishes (Manooch III \& 138 Haimovici, 1983; Saloman \& Naughton, 1984; Manooch, Mason \& Nelson, 1985; Campo et al., 139 2006; Sley et al., 2009; Fletcher, Batjakas \& Pierce, 2013).

\section{Hard bottom habitat}

141 Hard bottoms, or "live bottoms," are rocky habitats and conspicuous geological features on

142 the mainly soft sediment-dominated continental shelf within the SAB. In the Carolina Capes 143 region of the SAB (offshore of North and South Carolina) (Riggs et al., 1996) estimates of hard

144 bottom areal coverage vary on both latitudinal and longitudinal bases, with the greatest

145 proportions on the shelf to the south of Cape Lookout, North Carolina (Parker, Colby \& Willis, 146 1983; SAFMC, 1998). Extensive areas of hard bottom have been mapped and detailed geological

147 descriptions have been published for the arcuate coastal embayments of Onslow Bay

148 (southeastern North Carolina; Cape Lookout to the north and Cape Fear, North Carolina, to the 149 south), and Long Bay (southeastern NC and northeastern South Carolina; Cape Fear to Cape 150 Romaine, South Carolina) (Milliman, 1972; Parker, Colby \& Willis, 1983; Riggs, Cleary \& 151 Snyder, 1995; Cleary et al., 1996; Riggs et al., 1996; Ojeda et al., 2004; Denny et al., 2007;

152 Taylor et al., 2016; Wheaton, 2018; NC Division of Marine Fisheries, 2020). These bays are 
153 separated at Cape Fear by the Frying Pan Shoals, an area of shallow, shifting sediments that

154 extend offshore approximately $50 \mathrm{~km}$.

155 In general, hard bottoms within the Carolina Capes region are emergent areas of sedimentary

156 and biogenic rock (fossiliferous limestones) formed from earlier Pleistocene and Tertiary

157 deposits. They are typically surrounded by much more extensive areas of unconsolidated

158 sediments (mainly sands) deposited during the Holocene. Hard bottoms vary in emergent relief

159 from flat pavements with shallow veneers of sediment (Riggs et al., 1996), and typically

160 depauperate epifauna and a near absence of infauna (Renaud et al., 1996, 1997; Renaud, Syster

$161 \&$ Ambrose, 1999), to high-relief scarped hard bottoms (often called ledges) that may be meters

162 above the surrounding sands with vertical or sloped cliffs and combinations of undercuts and

163 overhangs (Riggs et al., 1996). Ledges in particular have rich communities of epifauna and rock-

164 boring infauna (Wenner et al., 1983).

165 Hard bottoms provide structural habitat for the settlement of benthic sessile foundation

166 species, including rich assemblages of sponges, scleractinian and octocorallian corals, ascidians,

167 and macroalgae (Struhsaker, 1969; Miller \& Richards, 1980; Wenner et al., 1983). The growth of

168 these sessile organisms contributes to hard bottom reef structural complexity. Compared to

169 adjacent soft-sediment dominated areas of the sea floor, hard bottoms create a striking contrast in

170 habitat that supports high richness and abundance of fishes (Sedberry \& Van Dolah, 1984;

171 Hopkinson, Jansson \& Schubauer-Berigan, 1991), invertebrates (Wenner et al., 1983; Peckol \&

172 Searles, 1984), and macroalgae (Schneider \& Searles, 1973, 1991; Schneider, 1976; Freshwater

$173 \&$ Idol, 2013). Specifically, hard bottom reefs are home to often large aggregations of small

174 schooling fishes, such as scads (Decapterus spp.) and young tomtate (Haemulon aurolineatum 
175 Cuvier in Cuvier and Valenciennes, 1830), that serve as important prey resources for many

176 pelagic and demersal piscivorous fishes (Kracker, Kendall \& McFall, 2008; Auster et al., 2013).

177 On hard bottoms off the coast of Georgia, competitive facilitation, an example of a BMII,

178 was observed as schools of round scad and tomtate retreated from multispecies associations of

179 pelagic piscivorous fish towards the seafloor, increasing predation opportunities for demersal

180 piscivorous fishes (Auster et al., 2009, 2013). Furthermore, Auster et al. (2009) observed round

181 scad and tomtate responding to the presence of pelagic predators by reducing nearest neighbor

182 distance and forming more polarized aggregations.

183 Polarity in fish schools describes the likelihood of alignment and synchronization of

184 movement among individuals (Shaw, 1978; Soria, Freon \& Chabanet, 2007). Increased

185 polarization is a common response to predators for many prey species that form aggregations and

186 has been found to reduce the vulnerability of prey aggregations (reviewed in Lima \& Dill, 1990).

187 In addition to increasing polarization, prey fishes use several other strategies to reduce

188 vulnerability to predators. Alternative strategies include temporal and spatial changes in forage

189 fish distribution (Campanella et al., 2019) and forming aggregations around physical objects,

190 which is hypothesized to be advantageous to prey by serving as a "schooling companion" (Klima

191 \& Wickham, 1971).

192 The abundance and taxonomic richness of species on hard bottom reefs and ledges facilitate

193 unique interspecies interactions that are often driven by enhanced feeding opportunities or

194 decreased vulnerability to predators (McFarland \& Kotchian 1982, Diamant and Shpigel 1985,

195 Baird 1993). For example, associations between blue runner, greater amberjack, and other large

196 piscivorous fishes have been observed during coordinated predatory foraging on hard bottoms

197 (Auster et al., 2009). Additionally, facilitative changes in predator behavior and prey reaction are 
198 linked to population processes (Auster et al., 2013) and patterns of temporal and spatial use of

199 habitat by both predators and prey (Campanella et al., 2019). Effects of such associations

200 containing multiple predators on prey mortality has been heavily debated and several studies

201 have reported both additive and reduced predation effects (reviewed in Sih, Englund \& Wooster, 202 1998).

203 Objectives

204 In this study, we examined association behavior between sand tiger sharks (STs), round scad 205 (RS), and scad mesopredators (MPs) using video records from a unique, long-term underwater 206 video installation sited on a hard bottom system off the coast of Cape Fear, North Carolina.

207 Based on video observations collected to assess the fish species assemblage (E Burge, 2020, 208 unpublished data) and video and in situ observations by Burge and others, we repeatedly noticed 209 the unusual association between STs and RS. Consequently, we hypothesized that association 210 behaviors between round scad and sand tigers were more frequent in the presence of pelagic 211 mesopredators than in their absence because the presence of mesopredators represents a potential 212 predation threat for round scad. Strength of the association behavior was believed to be a 213 response to mesopredators that reflects round scad vulnerability. We also suspect that 214 aggregations of round scad may be mutually beneficial to sand tiger sharks by providing 215 camouflage (Auster et al., 2013) and increasing predation opportunities on mesopredators.

216 Direct, visual observations of wild behavior of sand tiger sharks are very limited (but see Smith, 217 Scarr \& Scarpaci, 2010; Barker, Peddemors \& Williamson, 2011), and this species is currently 218 IUCN Red listed globally as Vulnerable, making research and conservation efforts necessary for 219 protection of this species. Investigating this association behavior may be insightful for a deeper 220 understanding of predation strategies of sand tiger sharks, protective behaviors of a common 
221 prey species, and contribute knowledge of trophic dynamics on hard bottom reefs in the South 222 Atlantic Bight.

223

\section{Materials \& Methods}

Study site and infrastructure

227

228

229

230

231

232

233

234

235

236

237

238

239

240

242

243

241 View Into The Blue ${ }^{\circledR}$ (Boulder, CO) cameras with CleanSweep ${ }^{\mathrm{TM}}$ hardware were used for all

Video collected in this project are from SharkCam, an underwater, live-streaming camera, publicly-viewable from https://explore.org/livecams/oceans/shark-cam (Explore.org, Los Angeles, CA). The camera is sited beneath Frying Pan Tower $\left(33^{\circ} 29^{\prime} \mathrm{N}, 77^{\circ} 35^{\prime} \mathrm{W}\right)$ which is located at the seaward edge of Frying Pan Shoals, approximately $50 \mathrm{~km}$ off the coast of Cape Fear, North Carolina. Frying Pan Shoals is within the biogeographic Carolina Province (Cape Hatteras to Cape Canaveral, Florida), a warm-temperate to subtropical zone of the Western Atlantic Region (Floeter et al., 2008; Briggs \& Bowen, 2012, 2013; Toonen et al., 2016). The camera is attached to a horizontal support at the base of Frying Pan Tower in about $15 \mathrm{~m}$ of water and is surrounded by an expansive area of natural hard bottom (Riggs et al., 1996; NC Division of Marine Fisheries, 2020) and steel debris, such as large pipes, beams, and gratings, from the exterior of the tower (Collins Engineers Inc., 2010)

(https://www.youtube.com/playlist?list=PLK1g13VpyT6oYUJL7U3hRPIt2U5L_mcKL). To date, videos from SharkCam have been used to identify 116 temperate and tropical marine fish species (November 2014-February 2020) (Burge, O’Brien \& jon-newbie, 2020). footage captured (https://www.viewintotheblue.com/)) The cameras used (six during the span of this project) featured HD 720p (November 2014-July 2016 footage) or HD 1080p (after October 
2442016 ) video resolution, $360^{\circ}$ pan-tilt-zoom that rotated on a pre-determined schedule, or with

245 manual remote control, and a field of view of $62^{\circ} \times 37^{\circ}$ (horizontal $\times$ vertical). Automatic white

246 balance (color control) was enabled in April 2017 to more closely approximate surface light for

247 color correction. Power is provided by a solar installation atop Frying Pan Tower and data

248 transmission used a line-of-sight radio to shore (Burge, O’Brien \& jon-newbie, 2020)

249 Video selection and analysis

250 SharkCam video files containing sand tiger shark Carcharias taurus (STs) records were

251 extracted from a larger video database of all fish species occurrences gathered from non-

252 consecutive, 20-min clips $(n=1024)$ analyzed as part of a larger community analysis project $(\mathrm{E}$

253 Burge 2020, unpublished data). Video files were recorded during local daylight hours between

254 November 2014 and January 2019.

255 All 20-min clips containing STs were re-analyzed to confirm shark identification, presence or 256 absence of round scad (RS) Decapterus punctatus or a visually indistinguishable species, such as 257 mackerel scad D. macarellus (Cuvier in Cuvier and Valenciennes, 1833) or redtail scad D. tabl 258 Berry, 1968, and the identification of mesopredators (MPs). Duration of the STs on screen 259 (seconds) was recorded to obtain average observation time.

260 This more detailed analysis of clips from the larger video database resulted in the rejection of 261 some data records $(n=26)$ because the initial shark identification was not confirmed $(\mathrm{n}=11 \mathrm{clips})$, 262 only a fleeting glimpse of STs was available and/or visibility was poor $(n=12)$, or the original 263 video could not be located $(n=3)$. Poor visibility compromised identification of RS or MPs. To 264 these confirmed STs records from the larger database we were able to add 24 clips that contained 265 STs from other video files not previously included in the larger video database by using more 266 recently analyzed clips, personal observations, or reports from citizen scientists recorded with the 
267 live video stream on-line (https://explore.org/livecams/oceans/shark-cam). In these added clips,

268 the shark was located and a 20-min clip of video was analyzed as described with the shark

269 centered in the middle. In total, 216 clips with the confirmed presence of STs were analyzed.

270 Clips with STs were reviewed for the simultaneous co-occurrence of RS and assigned a

271 descriptive category of the association behavior between them using the following categories: no

272 visible interaction (NVI), loosely associated (LA), and tightly associated (TA) (Figure 1). No

273 visible association was defined as both species moving independently of each other or in

274 opposing directions and with their heads oriented in different directions. Loosely associated

275 aggregations were defined as both species moving in a similar direction, their heads oriented in a

276 similar direction, and RS maintaining an estimated five scad body lengths or more from STs and

277 other school members. Tightly associated aggregations were defined as both species moving as

278 one entity, their heads oriented in the same direction, and RS maintaining less than five

279 estimated body lengths from STs and other school members. These behaviors represent a

280 spectrum of association that we hypothesize correlates with the vulnerability of RS to predation

281 in response to the presence of pelagic mesopredators (MPs); NVI representing the least

282 vulnerable and TA representing the most vulnerable. Video files with multiple sightings of STs

283 were treated as independent occurrences if shark observations were separated by 10-min or

284 greater. Multiple association observations within a 10-min interval were assigned a descriptive

285 category that best described the general association behavior of the recurring individuals. We

286 were not able to individually identify observed STs, however, we have no reason to believe that

287 this association behavior was limited to individual sharks given the multi-year duration over

288 which videos were collected. 

behavior, and so in order to assess this behaviorally-mediated response, we documented the 291 presence, identity, and occurrence of six pelagic MPs selected a priori within all 20-min video 292 clips that also contained STs. These were almaco jack (Seriola rivoliana, AJ), Atlantic bonito 293 (Sarda sarda, AB), blue runner (Caranx crysos, BR), crevalle jack (Caranx hippos, CJ), greater 294 amberjack (Seriola dumerili, GA), and little tunny (Euthynnus alletteratus, LT). Mesopredators 295 were selected based on preliminary observations of co-occurrence and predation attempts on RS recorded in the larger video database (E. Burge, 2020 unpublished data), published reports that suggest facilitated, or even cooperative, hunting (Auster et al., 2013, 2019), and shared characteristics of size (individual body size approximately $0.5 \mathrm{~m}-1.5 \mathrm{~m}$ ), highly active feeding behavior, and diet overlap (Manooch III \& Haimovici, 1983; Saloman \& Naughton, 1984; Manooch, Mason \& Nelson, 1985; Campo et al., 2006; Sley et al., 2009; Fletcher, Batjakas \& 301 Pierce, 2013).

Data analysis

Hierarchical cluster analysis using Bray-Curtis similarity on presence or absence data was used to illustrate the strength of co-occurrences between STs, RS, and each species of mesopredator in all recorded instances of sharks $(n=216)$. Statistical significance was tested with 1000 simulation permutations by Simprof $(\alpha=0.05)$ in PRIMER-e 6 (Plymouth Marine 307 Laboratory UK).

308 Pearson's chi-squared test $\left(\chi^{2}\right)$ was used to further investigate whether the frequency of 309 association behaviors between STs and RS were more commonly observed than expected if each 310 category of association had an equal chance of occurring (33\%). Equal likelihoods of each 311 association category occurring were assumed to represent a condition in which RS did not 
312 benefit from a close physical association with STs. Pearson's $\chi^{2}$ was also used to test the

313 frequency of association behaviors in the presence of one or more species of mesopredator. The

314 behavior categories were used to represent a continuum of association that reflected the relative

315 vulnerability of RS to pelagic MPs.

316 Multinomial logistic regression ('multinom', $R$ version 3.5.1) was used to calculate the log-

317 odds of association behavior (i.e. LA and TA behaviors) in the presence or absence of one or

318 more species of mesopredator. This analysis expanded on the results from the $\chi^{2}$ analysis, which

319 only compared the frequency of association behavior in the presence of MPs, by making

320 predictions of the frequency of association behavior in the presence and absence of MPs. Odds

321 ratios were exponentially transformed to obtain percentage values. We hypothesized that MPs

322 facilitated association behavior between STs and RS, therefore presence or absence data of MPs

323 was used as the independent variable and the association behavior was the dependent variable for

324 this analysis. We expected to see the log-odds of association behavior increase in the presence of 325 mesopredators, therefore the association category that represented the least degree of round scad 326 vulnerability, NVI, was used as the baseline in the analysis.

327

\section{Results}

329 All clips ( $\mathrm{n}=216)$ that contained one or more sand tigers sharks (STs) were used for hierarchical 330 cluster analysis with Bray-Curtis similarity. Among all clips, 186 (86\%) included simultaneous 331 observations of RS and STs and were used in multinomial logistic regression. Of the videos that

332 contained STs and RS, $159(85 \%)$ contained one or more species of MPs and were used in the 333 Pearson's $\chi^{2}$ (Table 1). Average observation time of STs and RS association behavior within 334 clips was $36 \pm 37.5 \mathrm{~s}$ (mean $\pm \mathrm{SD}$ ), range $3-254 \mathrm{~s}$, median $26 \mathrm{~s}$. 
336 In the absence of MPs and STs, RS were commonly observed swimming in unpolarized,

337 distributed schools as they foraged for plankton. Foraging and plankton feeding were inferred

338 from a commonly seen behavior where individuals flex their bodies slightly upward while

339 simultaneously opening the mouth (head-tipping), often with slight lateral adjustments,

340 presumably to ingest individual plankters (https://youtu.be/7 i8hoQXeAU; Table S1).

341 When STs were not observed and MPs were actively foraging on RS, RS responded by

342 forming denser schools (i.e. reducing nearest neighbor distance), and often retreated to the sea

343 floor or associated with the structure of Frying Pan Tower (https://youtu.be/IesLMb9OStw,

344 https://youtu.be/CTwih5UYaqw, https://youtu.be/CIFLIu2FVfA; Table S1).

345 During LA behavior with STs, RS exhibited unpolarized schooling behaviors, but maintained 346 proximity and speed with the STs (https://youtu.be/ CIqWVUprmU). During TA aggregation

347 behavior, RS decreased distance to nearest neighbor and STs, and moved with the STs as a

348 highly coordinated group (https://youtu.be/P37lg7iiDJo; Table S1).

349 Distinct transitions between behavioral categories were rarely observed, and the few

350 observed transitions captured the movement from LA aggregations to TA aggregations (Figure

351 2). During these observations, RS displayed an immediate response (less than one second) to

352 MPs. In some of these occurrences, RS can be described as "pulsating" around the shark, as they

353 transitioned constantly between a LA and TA state (https://youtu.be/9WuEyByf Pw,

354 https://youtu.be/1Ss-AvAMkVg, Table S1).

355 Predation attempts

356 Regardless of the species involved, apparently successful piscivorous predation seen on

357 SharkCam is exceedingly rare (E Burge, 2020, unpublished data). During data collection from 
358 1024, 20-min intervals of video $(>340 \mathrm{~h})$, we recorded all likely successful fish-on-fish predation

359 events and noted the species involved. Only a small number of observations of STs predation

360 attempts on MPs or other species were made $(n=5$, Table 2$)$ and these were always on prey

361 species much larger than round scad. Attempted predation was documented on two MPs species,

362 little tunny and blue runner, with two additional attempts on gag Mycteroperca microlepis

363 (Goode and Bean, 1879) and red drum Sciaenops ocellatus (Linnaeus, 1766)). Additionally, STs

364 were only observed making predation attempts on other fishes when tightly associated with RS,

365 with no observations of attempted predation during NVI and LA behaviors. The timing of these

366 events did not suggest a bias towards crepuscular feeding although a very small sample size

367 currently exists (Table 2).

368 During these rare phenomena, sand tiger sharks made quick lunges toward approaching

369 fishes that appeared oblivious to the presence of the STs, presumably due to shrouds of RS

370 tightly associated with the shark (Figure 3). Although STs were never observed capturing prey

371 during these attempts, it appeared that schools of RS concealed the presence of STs and attracted

372 scad predators to the STs (see videos in Table 2).

373 Descriptive frequencies

374 Sand tiger sharks are fall-winter-spring visitors seen most frequently during cool months

375 (21.3\% overall frequency of occurrence among all months, $n=1024$; Figure 4). Round scad are

376 ubiquitous during cool months and appear to depart in May-June and September-October

377 (64.8\% overall frequency of occurrence among all months, $n=1024$; Figure 4), but are most

378 frequently seen during periods of STs residency. The combinatorial frequency of occurrence for

379 these two species (co-occurrence) was $13.8 \%$ within the 1024 videos. Additionally, the 
380 frequency of videos (of 1024) that contained STs, RS, and one or more species of up to six

381 different MPs was 16.3\% (combinatorial frequency of occurrence for $3+$ species) (Table 1).

382 However, in videos selected because they contained STs (100\% frequency of occurrence,

$383 \mathrm{n}=216)$, RS were much more likely to be seen ( $86.1 \%$ frequency of occurrence), and the

384 likelihood of this co-occurrence was strongly clustered with the presence of one or more MPs

385 species (Figure 5) (83.7\%, combinatorial frequency of occurrence for $3+$ species). Of the six

386 species of MPs selected for this study, four species (almaco jack, blue runner, little tunny, and

387 Atlantic bonito) were more frequently observed within the data set of only STs videos $(n=216)$

388 than the SharkCam occurrence data set $(\mathrm{n}=1024)$ (Table 1).

389 Association behavior

390 Sand tiger sharks and RS clustered together the strongest (92.5\%), while MPs had lower

391 similarities (Figure 5). Among MPs, GA was significantly clustered with RS and STs and had

392 the highest similarity value of all MPs (63.4\%). Almaco jack (AJ; 54.2\% similarity) and BR

393 (37.9\% similarity) were also significantly clustered with STs, RS, and GA, while LT, CJ, and

394 AB were not significantly clustered within the group.

395 Analysis of the 186 videos containing co-occurrence of STs and RS resulted in 40

396 observations of NVI, 58 observations of LA behavior, and 88 observations of TA behavior

397 without regard to the presence or absence of MPs (Figure 6). In the presence of MPs the

398 frequency of LA and TA behaviors increased. NVI was least frequently observed ( $\mathrm{n}=33)$, and TA

399 behavior was most frequently observed $(\mathrm{n}=79)$. There was a significant difference in the

400 observed occurrences of behavioral categories compared to their expected frequencies, assuming

401 equal likelihoods of occurrence in the presence of MPs (Pearson's $\chi^{2}=20.981 ;$ df $2 ; p<0.000$ ).

402 Compared to no visible association, the log-odds of round scad being loosely associated with 
403 STs was $82.9 \%$ greater, and tightly associated behavior was $196 \%$ greater in the presence of

404 mesopredators, but these results were not statistically significant (LA, $p=0.727 ; \mathrm{TA}, \mathrm{p}=0.218$ ),

405 likely due to the number of NVI behaviors seen even when MPs were present.

406

407 Discussion

408 Based on SharkCam underwater video observations conducted over more than 5 years and 409 representing over 340 hours of underwater footage, we demonstrate that round scad (RS) are 410 significantly more likely to be associated with sand tiger sharks (STs) in the presence of potential 411 scad mesopredators (MPs), than in their absence. This example of a behaviorally-mediated 412 indirect interaction (BMII) has important implications for trophic energy transfer on hard 413 bottoms in the SAB.

414 Round scad are one of the most abundant pelagic, planktivorous fish species observed on 415 hard bottom habitats (Lindquist \& Pietrafesa, 1989; Rountree, 1990; Burge et al., 2012), and 416 high densities of RS are especially apparent on mid-shelf live bottoms of the SAB in winter 417 (Hales Jr., 1987). Under these circumstances, MPs are likely dependent on RS and similar 418 species such as mackerel scad D. macarellus and redtail scad D. tabl as primary prey resources, 419 especially in cooler months. Given this, it was important to investigate round scad association 420 behavior with sand tiger sharks and be aware that this interaction may relate to trophic transfer 421 and mesopredator control. We have no reason to believe this STs and RS association behavior is 422 unique to the hard bottom habitat off Cape Fear, North Carolina, therefore describing this 423 behavior and its stimulus aids in understanding trophic interactions and prey strategies that 424 influence predation success for pelagic predators. 
425

426

427

428

429

430

431

432

433

434

435

436

437

438

439

440

441

442

443

444

445

446

447

While the possibility of benefit to STs as increased predation opportunities remains an open question, available observations (see videos in Table 2) provide evidence that STs use this association to perform an undocumented predation strategy. The concealment provided to STs by RS and the attraction of MPs to the shark suggest that this association behavior facilitates the feeding and foraging behavior of sand tiger sharks (Table 2). Feeding behaviors and bite kinematics in captive $C$. taurus have been described (Ferrara et al., 2011; Moyer, Shannon \& Irschick, 2019), but foraging behavior in wild STs remains unclear, although several lines of evidence suggest that crepuscular and night foraging are probable in this species, with a need for substantial additional research (Hammerschlag et al., 2017). For example, Kneebone et al. (2018) report that juvenile sand tigers are more active at night in a nursery area of Plymouth, Kingston, Duxbury (PKD) Bay, Massachusetts. Using acoustic detections, accelerometer data, geospatial modelling, and field observations Kneebone at al. (2018) inferred that foraging behavior may be an important aspect of increased activity.

Admittedly, the limited field of view of SharkCam served as a constraint to fully observe behavior between STs, RS, and MPs because interactions occurred rapidly and in threedimensional space (see videos in Table S1). In this study, occurrences of MPs outside the perspective of SharkCam undoubtedly influenced events captured on camera, and this is likely responsible for many of the observations of loosely associated (LA) and tightly associated (TA) behaviors that occurred in the absence of MPs (STs+RS-MPs, $n=27)$. One or more species of selected MPs occurred in approximately $84 \%$ of videos containing STs and RS (Table 1).

Additionally, many other species of potential scad mesopredators are also present at Frying Pan Tower, including a diverse assemblage of demersal piscivores, and other pelagic species not designated as MPs in analyses (Table S2). Recent work by Brown et al. (2020), also on sand 
448 tiger sharks in North Carolina, has revealed that the presence of the sharks alters short-term reef

449 fish community richness on shipwrecks, with the prevalence of pelagic mesopredators elevated,

450 and those of demersal mesopredators depressed. They suggest that these differences in richness

451 may be behaviorally-mediated responses attributed to mesopredator optimization of foraging

452 strategy, with sharks as short-term drivers of spatial and temporal community composition for

453 mesopredators. Given this, it is likely that there are few circumstances when aggregations of

454 round scad are not exposed to potential predators. The inclusion of STs+RS-MPs videos in the

455 multinomial logistic regression likely resulted in the lack of statistical significance $(\mathrm{p}=0.727$ for

456 LA and $\mathrm{p}=0.218$ for TA), despite the relatively large increases in the odds of association

457 behavior as association strength increased ( $82.9 \%$ for LA and $196 \%$ for TA). This pattern is

458 supported by the results of the chi-square analysis that show the frequency of occurrence of

459 association behavior increased with association strength ( $p<0.000$, Figure 6).

460 In research analyzing predator influence on prey behavior, Seghers (1974) hypothesized that

461 guppies formed schools because they were always exposed to predation threats. Constant

462 exposure to predators provides a strong explanation for why round scad are observed forming

463 associations with sand tiger sharks when designated MPs are not seen on SharkCam. While

464 observations of round scad association with sand tiger sharks in the absence of MPs observations

465 may be a result of sampling bias (i.e. MPs were present but not observed on camera), it suggests

466 that aggregation behavior is driven by perceived predation risk assessed by the scad, and further

467 suggests near constant exposure to mesopredators. Experimental manipulation of mesopredators,

468 their prey, and higher trophic-level predator presence have tested perceived predation risk to prey

469 and mesopredators in marine (del Mar Palacios et al. 2016) and terrestrial (Gordon et al., 2015)

470 settings - one commonality that emerges is that the presence of a high trophic-level predator 
471 alleviates perceived risk to prey by providing a "refuge effect" associated with behavioral

472 changes in prey.

473 For example, the mackerel scad Decapterus macarellus, an ecologically similar and

474 sympatric relative of round scad D. punctatus, associated with goliath grouper Epinephelus

475 itajara (Lichtenstein, 1822) presumably to reduce their vulnerability to predation by the horse-

476 eye jack Caranx latus Agassiz in Spix and Agassiz, 1831. Mackerel scad were described as

477 forming a dense aggregation around the grouper while under threat by jacks, and the school of

478 scad moved with the grouper as one unit. The authors concluded that this behavior was likely

479 advantageous for mackerel scad by reducing their risk of predation by a mesopredator (jack) that

480 was itself potential prey for the grouper (Macieira et al., 2010).

481 Behavioral descriptions of RS and STs association were created to classify three distinct

482 levels of association based on preliminary observations. Inclusion of a continuous, quantitative

483 variable to measure aggregation strength may have increased the accuracy of identifying round

484 scad responses to mesopredators but was not necessary given how distinct existing behavioral

485 categories were. Nearest neighbor distance is a structural measurement of fish aggregations and

486 it is used to calculate the positional preference of individual fish within an aggregation based on

487 the positions and movements of adjacent fish (Parrish, Viscido \& Grunbaum, 2002). Evidence

488 supports that synchronization and group coordination are mediated by an individual's

489 interactions with nearest group members (Soria, Freon \& Chabanet, 2007; Ballerini et al., 2008;

490 Niizato \& Gunji, 2011). We visually estimated nearest neighbor distance of round scad to other

491 aggregation members and to sand tiger sharks to incorporate a measure of aggregation structure

492 into our behavioral descriptions in order to reduce observer bias. Conventionally, model

493 simulations have been effectively used to understand the mechanisms that influence strength, 
494 response to stimulus, and coordination of fish schools (Huth \& Wissel, 1992; Parrish, Viscido \&

495 Grunbaum, 2002). Observations of RS becoming more aggregated in response to perceived

496 predation threats are consistent with prior literature (Rountree \& Sedberry, 1991; Auster et al.,

$4972009,2013)$. Reduction in nearest neighbor distance and increased polarity likely facilitates more

498 efficient communication between school members which enhances group synchrony and

499 coordination (Rieucau et al., 2015).

500 In-situ marine field experiments analyzing fish aggregation dynamics are uncommon, likely

501 given the difficulty to track individual fish in an open setting. Dual frequency identification

502 sonar (DIDSON) has recently become a reliable method to conduct in-situ analysis of fish

503 schooling behavior and has the capability of monitoring the movement of individual fish

504 (Moursund, Carlson \& Peters, 2003; Boswell, Wilson \& Cowan, 2008; Price, Auster \& Kracker, 505 2013; Rieucau et al., 2016). Auster et al. (2013) used DIDSON techniques to effectively analyze

506 prey distribution during predator-prey interactions similar to those observed in this study on hard 507 bottoms in the SAB. DIDSON analysis would support more quantitative data on the structure of 508 associations between RS and STs, but was not necessary to understand interactions between RS 509 and MPs and would introduce additional cost for support and maintenance.

510 Sharks were always the nucleus of association for round scad in our study. We hypothesized

511 that proximity to sharks by round scad, in addition to changes in scad polarization and reduced

512 nearest neighbor distance, served as an additional predation defense for round scad against

513 mesopredators. Although we focused on association as protective for round scad with sharks, it is

514 important to consider other potential explanations for this behavior.

515 Fuller and Parsons (2019) reported observations of association between RS and several 516 species of sharks. In the Gulf of Mexico, aggregations of round scad and another carangid, 
517 Atlantic bumper (Chloroscombrus chrysurus (Linnaeus, 1766)), associated with blacktip sharks

518 (Carcharhinus limbatus (Müller and Henle, 1839)), spinner sharks (Carcharhinus brevipinna

519 (Müller and Henle, 1839)), and blacknose sharks (Carcharhinus acronotus (Poey, 1860)). In situ

520 observations of association between RS and STs had not been previously described prior to the

521 current study, but photographs available on-line document associations between round scad and

522 sand tiger sharks on North Carolina reefs and wrecks

523 (https://ncaquariums.wildbook.org/gallery.jsp), and these are mentioned by Fuller and Parsons

524 (2019). Their potential explanations for association behavior include protection from

525 mesopredator predation, optmotor responses (Shaw \& Tucker, 1965), and scatophagy on shark

526 fecal clouds. We did not document the frequency of round scad feeding during associations or

527 observe foraging on fecal clouds, but round scad foraging for plankton was common during

528 observations (Table S1). As fish forage, especially pelagic planktivores like round scad, they

529 become more vulnerable to predation; therefore, future studies should consider foraging benefits

530 and how associations with sharks reduced vulnerability during foraging. It is also important to

531 continue to explore the possible benefit of this association to sand tiger sharks to fully

532 understand how this association influences trophic interactions.

533

\section{Conclusions}

535 Based on underwater video observations from SharkCam, we hypothesized that association

536 behaviors between round scad and sand tiger sharks were more frequent in the presence of

537 pelagic mesopredators than in their absence because the presence of mesopredators represents a

538 potential predation threat for round scad. Scad were shown to be significantly more likely to be

539 tightly associated with sand tiger sharks in the presence of mesopredators, compared to in their 
540 absence. This example of a behaviorally-mediated indirect interaction suggests that the presence

541 of a large predator alleviates perceived risk to prey from mesopredators. These results illuminate

542 a previously undescribed behaviorally-mediated indirect interaction with important consequences

543 for trophic transfer and mesopredator control on hard bottom habitats, and supports the usage of

544 long-term underwater camera installations for addressing questions in marine ecology.

545

546 Acknowledgments

547 The authors thank the following institutions and individuals for their time and expertise. Camera

548 installation and ongoing maintenance collaborators included Trevor Mendelow (View Into the

549 Blue, https://www.viewintotheblue.com/; Teens4Oceans, https://teens4oceans.org/), Richard

550 Neal (Frying Pan Tower, https://fptower.org/), Jim Atack (F/V In Sea State), and at Explore.org,

551 Jonathan Silvio, Courtney Johnson, Joe Pfifer, and Candice Rusch (https://explore.org/about-us).

552 Field and tower volunteers included Steve Luff, Matt Davin, Frederick Farzanegan, Sondra

553 Vitols, Cody Sweitzer, David Kish, Saylor Vann, David Wood, Adam Greene, Reed Winn, Doug

554 Noble, Brooke Briza, Dan Madigan, Zach Hart, Brian Atack, and Steven Seeber. Preliminary

555 video observations for the presence of sand tiger sharks were completed by the following

556 participants in the Coastal Carolina University (CCU) QEP project MSCI 399Q Fish Community

557 Monitoring, fall 2015: Chris O’Brien, Randy Fink, John Rainey, and Kyle Gallion; spring 2016:

558 Randy Fink, Rachel Stout, Ashley Sutton, and Kyle Gallion; fall 2016: Lauren Stevens, Olivia

559 Bertelsen, Christine Casterline, Dave Klett, Kelly McConnaughey, and Emily Otstott; spring

560 2017: Dakota Hughes, Josh Dusci, Kyle Gallion, Megan Brewer, Macy McCall, Tyler McKee,

561 and Derek Bussey; fall 2017: Devon Carey, Jenna Haberle, Theresa Hegarty, Tyler McKee, Gary

562 Sturm, Cody Sweitzer, and Rebecca Wheeler; spring 2018: Tyler McKee, Cody Sweitzer, Layla 
563 Elfiki, Megan Wise, and Kyle Gallion; fall 2018: Cody Sweitzer, Faith Saupe, Jessica Pollack,

564 Jared Smith, Amberlynn Fowler, and Kaelen Reed; spring 2019: Catherine Costlow, Peyton

565 Hartenstein, Chloe Keller, Casey Ludwick, Hailey Metzger, Maariyah Najeeb, Max Pagliari,

566 Jessica Pollack, Jessica Sanders, Faith Saupe, and Ryan Ware; fall 2019: Kylie Bostick, Victoria

567 Campbell, Sydney Davis, Shayne Doone, Janina Jones, Casey Majer, Cheyanne Rufener, Jessica

568 Sanders, Faith Saupe, and Jared Smith.

569 Juliana Harding (Marine Science, CCU) assisted with synthesizing temperature data. Lindsey

570 Bell (Mathematics and Statistics, CCU) and Derek Crane (Biology, CCU) provided guidance on

571 probability and statistical analyses.

572 The authors thank Avery Paxton (NOAA National Centers for Coastal Ocean Science), and

573 Rob Condon (Young Scientist Academy, https://www.youngscientistacademy.org/), and one

574 anonymous reviewer for providing critical feedback and helping to improve this manuscript.

575

576 References

577 Auster PJ, Cortés J, Alvarado JJ, Beita-Jiménez A, Auster PJ, Cortés J, Alvarado JJ, Beita-

578 Jiménez A. 2019. Coordinated hunting behaviors of mixed-species groups of piscivores and

579 associated species at Isla del Coco National Park (Eastern Tropical Pacific). Neotropical

580 Ichthyology 17:e180165. DOI: 10.1590/1982-0224-20180165.

581 Auster PJ, Godfrey J, Watson A, Paquette A, McFall G. 2009. Behavior of prey links midwater

582 and demersal piscivorous reef fishes. Neotropical Ichthyology 7:109-112.

583 Auster PJ, Kracker L, Price V, Heupel E, McFall G, Grenda D. 2013. Behavior webs of

584 piscivores at subtropical live-bottom reefs. Bulletin of Marine Science 89:377-396. DOI:

585 10.5343/bms.2011.1123. 
586 Baird T. 1993. A new heterospecific foraging association between the puddingwife wrasse,

587 Halichoeres radiatus, and the bar jack, Caranx ruber: Evaluation of the foraging consequences.

588 Environmental Biology of Fishes 38:393-397. DOI: 10.1007/BF00007535.

589 Ballerini M, Cabibbo N, Candelier R, Cavagna A, Cisbani E, Giardina I, Lecomte V, Orlandi A,

590 Parisi G, Procaccini A, Viale M, Zdravkovic V. 2008. Interaction ruling animal collective

591 behavior depends on topological rather than metric distance: evidence from a field study.

592 Proceedings of the National Academy of Sciences 105:1232-1237. DOI:

593 10.1073/pnas.0711437105.

594 Barker SM, Peddemors VM, Williamson JE. 2011. A video and photographic study of

595 aggregation, swimming and respiratory behaviour changes in the grey nurse shark (Carcharias

596 taurus) in response to the presence of SCUBA divers. Marine and Freshwater Behaviour and

597 Physiology 44:75-92. DOI: 10.1080/10236244.2011.569991.

598 Beard DW, Dess GG. 1988. Modeling organizational species' interdependence in an ecological

599 community: An input-output approach. Academy of Management Review 13:362-373. DOI:

600 10.5465/amr.1988.4306941.

601 Bond ME, Babcock EA, Pikitch EK, Abercrombie DL, Lamb NF, Chapman DD. 2012. Reef

602 sharks exhibit site-fidelity and higher relative abundance in marine reserves on the

603 Mesoamerican Barrier Reef. PLOS ONE 7:e32983. DOI: 10.1371/journal.pone.0032983.

604 Boswell KM, Wilson MP, Cowan JH. 2008. A semiautomated approach to estimating fish size,

605 abundance, and behavior from Dual-Frequency Identification Sonar (DIDSON) data. North

606 American Journal of Fisheries Management 28:799-807. DOI: 10.1577/M07-116.1.

607 Briggs JC, Bowen BW. 2012. A realignment of marine biogeographic provinces with particular

608 reference to fish distributions. Journal of Biogeography 39:12-30. DOI: 10.1111/j.1365-

609 2699.2011.02613.x.

610 Briggs JC, Bowen BW. 2013. Marine shelf habitat: biogeography and evolution. Journal of

611 Biogeography 40:1023-1035. DOI: 10.1111/jbi.12082.

612 Brown CM, Paxton AB, Taylor JC, Van Hoeck RV, Fatzinger MH, Silliman BR. 2020. Short-

613 term changes in reef fish community metrics correlate with variability in large shark occurrence.

614 Food Webs 24:e00147. DOI: 10.1016/j.fooweb.2020.e00147. 
615 Burge EJ, Atack JD, Andrews C, Binder BM, Hart ZD, Wood AC, Bohrer LE, Jagannathan K.

616 2012. Underwater video monitoring of groupers and the associated hard-bottom reef fish

617 assemblage of North Carolina. Bulletin of Marine Science 88:15-38. DOI:

$61810.5343 / \mathrm{bms} .2010 .1079$.

619 Burge EJ, O'Brien CE, jon-newbie. 2020. SharkCam fishes: A guide to nekton at Frying Pan 620 Tower. Los Angeles: Explore.org Ocean Frontiers, https://explore.org/livecams/oceans/shark621 cam.

622 Campanella F, Auster PJ, Taylor JC, Muñoz RC. 2019. Dynamics of predator-prey habitat use 623 and behavioral interactions over diel periods at sub-tropical reefs. PLOS ONE 14:e0211886. 624 DOI: 10.1371/journal.pone.0211886.

625 Campo D, Mostarda E, Castriota L, Scarabello MP, Andaloro F. 2006. Feeding habits of the 626 Atlantic bonito, Sarda sarda (Bloch, 1793) in the southern Tyrrhenian sea. Fisheries Research 627 81:169-175. DOI: 10.1016/j.fishres.2006.07.006.

628 Carlson JK, McCandless CT, Cortés E, Grubbs RD, Andrews KI, Musick JA. 2009. An update 629 on the status of the sand tiger shark, Carcharias taurus, in the northwest Atlantic Ocean. NOAA 630 Technical Memorandum NMFS-SEFSC-585: U.S. Department of Commerce, National Oceanic 631 and Atmospheric Administration, National Marine Fisheries Service, Southeast Fisheries Science 632 Center, Panama City Laboratory, Panama City, FL.

633 Cavanagh RD, Kyne PM, Fowler SL, Musick JA, Bennett MB. 2003. The conservation status of 634 Australian chondrichthyans: Report of the IUCN Shark Specialist Group Australia and Oceania 635 Regional Red List Workshop. The University of Queensland, School of Biomedical Sciences, 636 Brisbane, Australia.

637 Chester AJ, Huntsman GR, Tester PA, Manooch CS. 1984. South Atlantic Bight reef fish 638 communities as represented in hook-and-line catches. Bulletin of Marine Science 34:267-279.

639 Chiaramonte G, Domingo A, Soto J. 2007.Carcharias taurus (Southwest Atlantic

640 subpopulation). The IUCN Red List of Threatened Species. Available at

641 http://dx.doi.org/10.2305/IUCN.UK.2009-2.RLTS.T3854A10132481.en (accessed December 9, 642 2020). 
643 Cleary WJ, Riggs SR, Marcy DC, Snyder SW. 1996. The influence of inherited geological

644 framework upon a hardbottom-dominated shoreface on a high-energy shelf: Onslow Bay, North 645 Carolina, USA. Geological Society, London, Special Publications 117:249-266. DOI:

646 10.1144/GSL.SP.1996.117.01.15.

647 Cole RG. 1994. Abundance, size structure, and diver-oriented behaviour of three large benthic 648 carnivorous fishes in a marine reserve in Northeastern New Zealand. Biological Conservation 649 70:93-99. DOI: 10.1016/0006-3207(94)90276-3.

650 Collins Engineers Inc. 2010. Structural inspection and assessment of the U.S. Coast Guard 651 Frying Pan Shoals Light Station. USCG Contract No. HSCG83-07-D-3WF172, USCG Task 652 Order No. HSCG83-10-J-PCU005, Collins Job 6277-40, U.S. Coast Guard, Civil Engineering 653 Unit Cleveland, Cleveland, Ohio.

654 Compagno LJ. 2001. Sharks of the world. An annotated and illustrated catalogue of shark 655 species known to date. Volume 2. Bullhead, mackerel and carpet sharks (Heterodontiformes, 656 Lamniformes and Orectolobiformes). Rome, p 55-62: Food \& Agriculture Organization of the 657 United Nations.

658 Creel S, Christianson D. 2008. Relationships between direct predation and risk effects. Trends in 659 Ecology \& Evolution 23:194-201. DOI: 10.1016/j.tree.2007.12.004.

660 Davis RW, Fuiman LA, Williams TM, Collier SO, Hagey WP, Kanatous SB, Kohin S, Horning 661 M. 1999. Hunting behavior of a marine mammal beneath the Antarctic fast ice. Science 283:993662 996. DOI: 10.1126/science.283.5404.993.

663 Denny J, Baldwin W, Schwab W, Gayes P, Morton R, Driscoll N. 2007. Morphology and texture 664 of modern sediments on the inner shelf of South Carolina's Long Bay from Little River Inlet to 665 Winyah Bay. U.S. Geological Survey Woods Hole Science Center, Woods Hole, Massachusetts: 666 U.S. Department of the Interior, U.S. Geological Survey.

667 Diamant A, Shpigel M. 1985. Interspecific feeding associations of groupers (Teleostei: 668 Serranidae) with octopuses and moray eels in the Gulf of Eilat (Agaba). Environmental Biology 669 of Fishes 13:153-159. DOI: 10.1007/BF00002584. 
670 Dill LM, Heithaus MR, Walters CJ. 2003. Behaviorally mediated indirect interactions in marine 671 communities and their conservation implications. Ecology 84:1151-1157. DOI: 10.1890/0012672 9658(2003)084[1151:BMIIIM]2.0.CO;2.

673 Donaldson PL, Clavijo IE. 1994. Diet of round scad (Decapterus punctatus) on a natural and an 674 artificial reef in Onslow Bay, North Carolina. Bulletin of Marine Science 55:501-509.

675 Dunbrack R, Zielinski R. 2003. Seasonal and diurnal activity of sixgill sharks (Hexanchus 676 griseus) on a shallow water reef in the Strait of Georgia, British Columbia. Canadian Journal of 677 Zoology 81:1107-1111. DOI: 10.1139/z03-087.

678 Emslie MJ, Cheal AJ, MacNeil MA, Miller IR, Sweatman HPA. 2018. Reef fish communities 679 are spooked by scuba surveys and may take hours to recover. PeerJ 6:e4886. DOI: $68010.7717 /$ peerj.4886.

681 Ferrara TL, Clausen P, Huber DR, McHenry CR, Peddemors V, Wroe S. 2011. Mechanics of 682 biting in great white and sandtiger sharks. Journal of Biomechanics 44:430-435. DOI: 683 10.1016/j.jbiomech.2010.09.028.

684 Fletcher N, Batjakas IE, Pierce GJ. 2013. Diet of the Atlantic bonito Sarda sarda (Bloch, 1793) 685 in the Northeast Aegean Sea. Journal of Applied Ichthyology 29:1030-1035. DOI: $68610.1111 /$ jai.12164.

687 Floeter SR, Rocha LA, Robertson DR, Joyeux JC, Smith-Vaniz WF, Wirtz P, Edwards AJ, 688 Barreiros JP, Ferreira CEL, Gasparini JL, Brito A, Falcón JM, Bowen BW, Bernardi G. 2008. 689 Atlantic reef fish biogeography and evolution. Journal of Biogeography 35:22-47.

690 Ford JR, Swearer SE. 2013. Shoaling behaviour enhances risk of predation from multiple 691 predator guilds in a marine fish. Oecologia 172:387-397. DOI: 10.1007/s00442-012-2508-4.

692 Frazier B, Paramore L, Rootes-Murdy K. 2019. 2018 review of the Atlantic States Marine 693 Fisheries Commission Fishery Management Plan for Coastal Sharks, 2017 Fishing Year. 694 Atlantic States Marine Fisheries Commission.

695 http://www.asmfc.org/uploads/file/5d00081cCoastalSharksFMPReview_2018.pdf.

696 Freshwater DW, Idol JN. 2013. Studies of North Carolina marine algae XIII. First reports of the 697 genus Cottoniella (Rhodophyta, Sarcomeniaceae). Marine Biodiversity Records 6. DOI:

$69810.1017 / \mathrm{S} 1755267213000651$. 
699 Fuller LN, Parsons GR. 2019. A note on associations observed between sharks and teleosts.

700 Southeastern Naturalist 18:489-498. DOI: 10.1656/058.018.0314.

701 Gelsleichter J, Musick JA, Nichols S. 1999. Food habits of the smooth dogfish, Mustelus canis,

702 dusky shark, Carcharhinus obscurus, Atlantic sharpnose shark, Rhizoprionodon terraenovae,

703 and the sand tiger, Carcharias taurus, from the northwest Atlantic Ocean. Environmental

704 Biology of Fishes 54:205-217. DOI: 10.1023/A:1007527111292.

705 Goldman KJ, Branstetter S, Musick JA. 2006. A re-examination of the age and growth of sand

706 tiger sharks, Carcharias taurus, in the western North Atlantic: the importance of ageing 707 protocols and use of multiple back-calculation techniques. Environmental Biology of Fishes 708 77:241. DOI: 10.1007/s10641-006-9128-y.

709 Gordon I. 1993. Pre-copulatory behaviour of captive sandtiger sharks, Carcharias taurus.

710 Environmental Biology of Fishes 38:159-164. DOI: 10.1007/BF00842912.

711 Gordon CE, Feit A, Grüber J, Letnic M. 2015. Mesopredator suppression by an apex predator

712 alleviates the risk of predation perceived by small prey. Proceedings of the Royal Society B:

713 Biological Sciences 282:20142870. DOI: 10.1098/rspb.2014.2870.

714 Govender A, Kistnasamy N, Van Der Elst RP. 1991. Growth of spotted ragged-tooth sharks

715 Carcharias taurus (Rafinesque) in captivity. South African Journal of Marine Science 11:15-19. 716 DOI: 10.2989/025776191784287718.

717 Hales Jr. SL. 1987. Distribution, abundance, reproduction, food habits, age and growth of round 718 scad, Decapterus punctatus, in the South Atlantic Bight. Fish. Bull. 85:251-268.

719 Hammerschlag N, Skubel R, Calich H, Nelson E, Shiffman D, Wester J, Macdonald C, Cain S, 720 Jennings L, Enchelmaier A, Gallagher A. 2017. Nocturnal and crepuscular behavior in 721 elasmobranchs: a review of movement, habitat use, foraging, and reproduction in the dark.

722 Bulletin of Marine Science 93:355-374. DOI: 10.5343/bms.2016.1046.

723 Haulsee DE, Fox DA, Breece MW, Brown LM, Kneebone J, Skomal GB, Oliver MJ. 2016 a.

724 Social network analysis reveals potential fission-fusion behavior in a shark. Scientific Reports 725 6:1-9. DOI: 10.1038/srep34087. 
726 Haulsee DE, Fox DA, Breece MW, Clauss TM, Oliver MJ. 2016b. Implantation and recovery of

727 long-term archival transceivers in a migratory shark with high site fidelity. PLOS ONE

728 11:e0148617. DOI: 10.1371/journal.pone.0148617.

729 Heupel M, Knip D, Simpfendorfer C, Dulvy N. 2014. Sizing up the ecological role of sharks as

730 predators. Marine Ecology Progress Series 495:291-298. DOI: 10.3354/meps10597.

731 Hopkinson C, Jansson B-O, Schubauer-Berigan J. 1991. Community metabolism and nutrient

732 cycling at Gray's Reef, a hard bottom habitat in the Georgia Bight. Marine Ecology Progress

733 Series 73:105-120. DOI: 10.3354/meps073105.

734 Hutchinson GE. 1959. Homage to Santa Rosalia or why are there so many kinds of animals? The 735 American Naturalist 93:145-159.

736 Huth A, Wissel C. 1992. The simulation of the movement of fish schools. Journal of Theoretical 737 Biology 156:365-385. DOI: 10.1016/S0022-5193(05)80681-2.

738 Kanno S, Schlaff AM, Heupel MR, Simpfendorfer CA. 2019. Stationary video monitoring 739 reveals habitat use of stingrays in mangroves. Marine Ecology Progress Series 621:155-168. 740 DOI: $10.3354 / \mathrm{meps} 12977$.

741 Kendall MS, Bauer LJ, Jeffrey CFG. 2009. Influence of hard bottom morphology on fish 742 assemblages of the continental shelf off Georgia, southeastern USA. Bulletin of Marine Science $74384: 265-286$.

744 Klima EF, Wickham DA. 1971. Attraction of coastal pelagic fishes with artificial structures.

745 Transactions of the American Fisheries Society 100:86-99. DOI: 10.1577/1548-

$746 \quad 8659(1971) 100<86: \mathrm{AOCPFW}>2.0 . \mathrm{CO} ; 2$.

747 Kneebone J, Winton M, Danylchuk A, Chisholm J, Skomal GB. 2018. An assessment of juvenile 748 sand tiger (Carcharias taurus) activity patterns in a seasonal nursery using accelerometer 749 transmitters. Environmental Biology of Fishes 101:1739-1756. DOI: 10.1007/s10641-018-08217504.

751 Kracker L, Kendall M, McFall G. 2008. Benthic features as a determinant for fish biomass in

752 Gray’s Reef National Marine Sanctuary. Marine Geodesy 31:267-280. DOI:

$75310.1080 / 01490410802466611$. 
754 Kulbicki M. 1998. How the acquired behaviour of commercial reef fishes may influence the 755 results obtained from visual censuses. Journal of Experimental Marine Biology and Ecology 756 222:11-30. DOI: 10.1016/S0022-0981(97)00133-0.

757 Latour RJ, Gartland J. 2020. Dynamics of the shark community in the Mid-Atlantic Bight.

758 Marine Biology 167:100. DOI: 10.1007/s00227-020-03720-y.

759 Lima SL, Dill LM. 1990. Behavioral decisions made under the risk of predation: a review and 760 prospectus. Canadian Journal of Zoology 68:619-640. DOI: 10.1139/z90-092.

761 Lindfield SJ, Harvey ES, McIlwain JL, Halford AR. 2014. Silent fish surveys: bubble-free diving 762 highlights inaccuracies associated with SCUBA-based surveys in heavily fished areas. Methods 763 in Ecology and Evolution 5:1061-1069. DOI: 10.1111/2041-210X.12262.

764 Lindquist DG, Pietrafesa LJ. 1989. Current vortices and fish aggregations: the current field and 765 associated fishes around a tugboat wreck in Onslow Bay, North Carolina. Bulletin of Marine 766 Science 44:533-544.

767 Macieira RM, Simon T, Pimentel CR, Joyeux J-C. 2010. Protection in the giant: goliath grouper 768 (Epinephelus itajara) as a refuge for mackerel scad (Decapterus macarellus). Marine 769 Biodiversity Records 3:e45. DOI: 10.1017/S1755267209991011.

770 Mallet D, Pelletier D. 2014. Underwater video techniques for observing coastal marine 771 biodiversity: a review of sixty years of publications (1952-2012). Fisheries Research 154:44-62. 772 DOI: 10.1016/j.fishres.2014.01.019.

773 Manooch III CS, Haimovici M. 1983. Foods of greater amberjack, Seriola dumerili, and almaco 774 jack, Seriola rivoliana (Pisces: Carangidae), from the South Atlantic Bight. Journal of the Elisha 775 Mitchell Scientific Society 99:1-9.

776 Manooch CS, Mason DL, Nelson RS. 1985. Foods of little tunny Euthynnus alletteratus 777 collected along the southeastern and Gulf coasts of the United States. Nippon Suisan Gakkaishi 778 51:1207-1218. DOI: 10.2331/suisan.51.1207.

779 del Mar Palacios M, Warren DT, McCormick MI. 2016. Sensory cues of a top-predator 780 indirectly control a reef fish mesopredator. Oikos 125:201-209. DOI: 10.1111/oik.02116. 
781 Matheson RH, Huntsman GR, Manooch CS. 1986. Age, growth, mortality, food and

782 reproduction of the scamp, Mycteroperca phenax, collected off North Carolina and South

783 Carolina. Bulletin of Marine Science 38:300-312.

784 McCauley DJ, McLean KA, Bauer J, Young HS, Micheli F. 2012. Evaluating the performance of 785 methods for estimating the abundance of rapidly declining coastal shark populations. Ecological 786 Applications 22:385-392. DOI: 10.1890/11-1059.1.

787 McFarland WN, Kotchian NM. 1982. Interaction between schools of fish and mysids.

788 Behavioral Ecology and Sociobiology 11:71-76. DOI: 10.1007/BF00300094.

789 Miller GC, Richards WJ. 1980. Reef fish habitat, faunal assemblages, and factors determining 790 distributions in the South Atlantic Bight. Proceedings of the Gulf and Caribbean Fisheries 791 Institute 32:114-130.

792 Milliman JD. 1972. Atlantic Continental Shelf and Slope of the United States - Petrology of the 793 Sand Fraction of Sediments, Northern New Jersey to Southern Florida. United States 794 Department of the Interior, Geological Survey.

795 Moursund RA, Carlson TJ, Peters RD. 2003. A fisheries application of a dual-frequency 796 identification sonar acoustic camera. ICES Journal of Marine Science 60:678-683. DOI: 797 10.1016/S1054-3139(03)00036-5.

798 Moyer JK, Shannon SF, Irschick DJ. 2019. Bite performance and feeding behaviour of the sand 799 tiger shark Carcharias taurus. Journal of Fish Biology 95:881-892. DOI:

800 https://doi.org/10.1111/jfb.14086.

801 Musick JA, Branstetter S, Colvocoresses JA. 1993. Trends in shark abundance from 1974 to 8021991 for the Chesapeake Bight region of the U.S. Mid-Atlantic Coast. U.S. Department of 803 Commerce, National Oceanic and Atmospheric Administration, National Marine Fisheries 804 Service.

805 Musick JA, Harbin MM, Berkeley SA, Burgess GH, Eklund AM, Findley L, Gilmore RG, 806 Golden JT, Ha DS, Huntsman GR, McGovern JC, Sedberry GR, Parker SJ, Poss SG, Sala E, 807 Schmidt TW, Weeks H, Wright SG. 2000. Marine, estuarine, and diadromous fish stocks at risk 808 of extinction in North America (exclusive of Pacific salmonids). Fisheries 25:6-30. DOI: 809 10.1577/1548-8446(2000)025<0006:MEADFS>2.0.CO;2. 
810 Naughton SP, Saloman CH, Vaught RN. 1986. Species profile of round scad Decapterus

811 punctatus (Cuvier 1829). U.S. Department of Commerce, National Oceanic and Atmospheric

812 Administration, National Marine Fisheries Service, Southeast Fisheries Science Center, Panama

813 City Laboratory, Panama City, FL, NOAA Technical Memorandum NMFS-SEFC-181.

814 NC Division of Marine Fisheries. 2020.Location of hard bottom habitat. Available at

815 http://portal.ncdenr.org/web/mf/habitat/hard-bottom (accessed February 5, 2020).

816 Niizato T, Gunji Y-P. 2011. Metric-topological interaction model of collective behavior.

817 Ecological Modelling 222:3041-3049. DOI: 10.1016/j.ecolmodel.2011.06.008.

818 NOAA Fisheries. 2019. 2018 Stock Assessment and Fishery Evaluation (SAFE) Report for 819 Atlantic Highly Migratory Species. Atlantic Highly Migratory Species Management Division, 820 NOAA Fisheries, Silver Spring, Maryland.

821 Ojeda GY, Gayes PT, Van Dolah RF, Schwab WC. 2004. Spatially quantitative seafloor habitat 822 mapping: example from the northern South Carolina inner continental shelf. Estuarine, Coastal 823 and Shelf Science 59:399-416. DOI: 10.1016/j.ecss.2003.09.012.

824 Paine RT. 1984. Ecological determinism in the competition for space: The Robert H. MacArthur 825 Award Lecture. Ecology 65:1339-1348. DOI: 10.2307/1939114.

826 Parker RO, Chester AJ, Nelson RS. 1994. A video transect method for estimating reef fish 827 abundance, composition, and habitat utilization at Gray's Reef National Marine Sanctuary, 828 Georgia. Fishery Bulletin 92:787-99.

829 Parker RO, Colby DR, Willis TD. 1983. Estimated amount of reef habitat on a portion of the 830 U.S. South Atlantic and Gulf of Mexico continental shelf. Bulletin of Marine Science 33:935831940.

832 Parrish JK, Viscido SV, Grunbaum D. 2002. Self-organized fish schools: an examination of 833 emergent properties. Biological Bulletin 202:296-305.

834 Paxton AB, Blair E, Blawas C, Fatzinger MH, Marens M, Holmberg J, Kingen C, Houppermans 835 T, Keusenkothen M, McCord J, Silliman BR, Penfold LM. 2019. Citizen science reveals female 836 sand tiger sharks (Carcharias taurus) exhibit signs of site fidelity on shipwrecks. Ecology 837 100:e02687. DOI: 10.1002/ecy.2687. 
838 Peckol P, Searles RB. 1984. Temporal and spatial patterns of growth and survival of invertebrate 839 and algal populations of a North Carolina continental shelf community. Estuarine, Coastal and 840 Shelf Science 18:133-143. DOI: 10.1016/0272-7714(84)90101-X.

841 Pollard D, Smith A. 2009.Carcharias taurus. The IUCN Red List of Threatened Species. 842 Available at http://dx.doi.org/10.2305/IUCN.UK.2009-2.RLTS.T3854A10132481.en (accessed 843 December 18, 2019).

844 Posey MH, Ambrose Jr. WG. 1994. Effects of proximity to an offshore hard-bottom reef on 845 infaunal abundances. Marine Biology 118:745-753. DOI: 10.1007/BF00347524.

846 Preisser EL, Bolnick DI, Benard MF. 2005. Scared to death? The effects of intimidation and 847 consumption in predator-prey interactions. Ecology 86:501-509. DOI: 10.1890/04-0719.

848 Price VE, Auster PJ, Kracker L. 2013. Use of high-resolution DIDSON sonar to quantify 849 attributes of predation at ecologically relevant space and time scales. Marine Technology Society 850 Journal 47:33-46. DOI: 10.4031/MTSJ.47.1.6.

851 Renaud PE, Ambrose Jr WG, Riggs SR, Syster DA. 1996. Multi-level effects of severe storms on 852 an offshore temperate reef system: Benthic sediments, macroalgae, and implications for fisheries. 853 Marine Ecology 17:383-398.

854 Renaud PE, Riggs SR, Ambrose Jr WG, Schmid K, Snyder SW. 1997. Biological-geological 855 interactions: Storm effects on macroalgal communities mediated by sediment characteristics and 856 distribution. Continental Shelf Research 17:37-56.

857 Renaud PE, Syster DA, AmbroseJr WG. 1999. Recruitment patterns of continental shelf benthos 858 off North Carolina, USA: effects of sediment enrichment and impact on community structure. 859 Journal of Experimental Marine Biology and Ecology 237:89-106.

860 Rieucau G, Fernö A, Ioannou CC, Handegard NO. 2015. Towards of a firmer explanation of 861 large shoal formation, maintenance and collective reactions in marine fish. Reviews in Fish 862 Biology and Fisheries 25:21-37. DOI: 10.1007/s11160-014-9367-5.

863 Rieucau G, Holmin AJ, Castillo JC, Couzin ID, Handegard NO. 2016. School level structural 864 and dynamic adjustments to risk promote information transfer and collective evasion in herring. 865 Animal Behaviour 117:69-78. DOI: 10.1016/j.anbehav.2016.05.002. 
866 Riggs S, Cleary W, Snyder S. 1995. Influence of inherited geologic framework on barrier 867 shoreface morphology and dynamics. Marine Geology 126:213-234. DOI: 10.1016/0025868 3227(95)00079-E.

869 Riggs SR, Snyder SW, Hine AC, Mearns DL. 1996. Hardbottom morphology and relationship to 870 the geologic framework; Mid-Atlantic continental shelf. Journal of Sedimentary Research 871 66:830-846. DOI: 10.1306/D4268419-2B26-11D7-8648000102C1865D.

872 Ritchie EG, Johnson CN. 2009. Predator interactions, mesopredator release and biodiversity 873 conservation. Ecology Letters 12:982-998. DOI: 10.1111/j.1461-0248.2009.01347.x.

874 Rountree RA. 1989. Association of fishes with Fish Aggregation Devices: effects of structure 875 size on fish abundance. Bulletin of Marine Science 44:960-972.

876 Rountree RA. 1990. Community structure of fishes attracted to shallow water fish aggregation 877 devices off South Carolina, U.S.A. Environmental Biology of Fishes 29:241-262. DOI: 878 10.1007/BF00001183.

879 Rountree R, Sedberry G. 1991. In-situ observations of the schooling behavior of planktivorous 880 fishes. Unpublished draft manuscript:DOI: 10.13140/RG.2.1.2371.5289. DOI:

881 10.13140/RG.2.1.2371.5289.

882 SAFMC. 1998. Final Habitat Plan for the South Atlantic Region: Essential fish habitat 883 requirements for fishery management plans of the South Atlantic Fishery Management Council.

884 North Charleston, SC. 457 p.+appendices: South Atlantic Fishery Management Council.

885 Saloman CH, Naughton SP. 1984. Food of crevalle jack (Caranx hippos) from Florida,

886 Louisiana, and Texas. NOAA Technical Memorandum NMFS-SEFC-134: U.S. Department of 887 Commerce, National Oceanic and Atmospheric Administration, National Marine Fisheries 888 Service, Southeast Fisheries Science Center, Panama City Laboratory, Panama City, FL.

889 Schmitz OJ, Krivan V, Ovadia O. 2004. Trophic cascades: the primacy of trait-mediated indirect 890 interactions. Ecology Letters 7:153-163. DOI: 10.1111/j.1461-0248.2003.00560.x.

891 Schneider CW. 1976. Spatial and temporal distributions of benthic marine algae on the 892 continental shelf of the Carolinas. Bulletin of Marine Science 26:133-151. 
893 Schneider CW, Searles RB. 1973. North Carolina marine algae. II. New records and observations 894 of the benthic offshore flora. Phycologia 12:201-211. DOI: 10.2216/10031-8884-12-3-201.1.

895 Schneider CW, Searles RB. 1991. Seaweeds of the southeastern United States: Cape Hatteras to 896 Cape Canaveral. Durham, NC: Duke University Press.

897 Sedberry G, Van Dolah R. 1984. Demersal fish assemblages associated with hard bottom habitat 898 in the South Atlantic Bight of the U.S.A. Environmental Biology of Fishes 11:241-258. DOI: 899 10.1007/BF00001372.

900 Seghers BH. 1974. Schooling behavior in the guppy (Poecilia reticulata): an evolutionary 901 response to predation. Evolution 28:486-489. DOI: 10.1111/j.1558-5646.1974.tb00774.x.

902 Shaw E. 1978. Schooling fishes. American Scientist 66:166-175.

903 Shaw E, Tucker A. 1965. The optomotor reaction of schooling carangid fishes. Animal 904 Behaviour 13:330-IN7. DOI: 10.1016/0003-3472(65)90052-7.

905 Sih A, Englund G, Wooster D. 1998. Emergent impacts of multiple predators on prey. Trends in 906 Ecology \& Evolution 13:350-355. DOI: 10.1016/S0169-5347(98)01437-2.

907 Sley A, Jarboui O, Ghorbel M, Bouain A. 2009. Food and feeding habits of Caranx crysos from 908 the Gulf of Gabès (Tunisia). Journal of the Marine Biological Association of the United 909 Kingdom 89:1375-1380. DOI: 10.1017/S0025315409000265.

910 Smale MJ, Booth AJ, Farquhar MR, Meÿer MR, Rochat L. 2012. Migration and habitat use of 911 formerly captive and wild raggedtooth sharks (Carcharias taurus) on the southeast coast of 912 South Africa. Marine Biology Research 8:115-128. DOI: 10.1080/17451000.2011.617756.

913 Smith K, Scarr M, Scarpaci C. 2010. Grey nurse shark (Carcharias taurus) diving tourism:

914 Tourist compliance and shark behaviour at Fish Rock, Australia. Environmental Management 915 46:699-710. DOI: 10.1007/s00267-010-9561-8.

916 Soria M, Freon P, Chabanet P. 2007. Schooling properties of an obligate and a facultative fish 917 species. Journal of Fish Biology 71:1257-1269. DOI: 10.1111/j.1095-8649.2007.01554.x.

918 Struhsaker P. 1969. Demersal fish resources: Composition, distribution, and commercial 919 potential of the continental shelf stocks off the southeastern United States. Fisheries Independent 920 Research 4:261-300. 
921 Taylor CJ, Paxton AB, Voss CM, Sumners BW, Buckel CA, Vander Pluym JL, Ebert EF, 922 Viehman TS, Fegley SR, Pickering EA, Adler AM, Freeman C, Peterson CH. 2016. Benthic 923 habitat mapping and assessment in the Wilmington-East Wind Energy Call Area, final report. 924 U.S. Department of the Interior, Bureau of Ocean Energy Management (BOEM). Atlantic OCS 925 Region, Sterling, VA. OCS Study BOEM 2016-003 and NOAA Technical Memorandum 196: 926 OCS Study BOEM 2016-003.

927 Teter S, Wetherbee B, Fox D, Lam C, Kiefer D, Shivji M. 2015. Migratory patterns and habitat 928 use of the sand tiger shark (Carcharias taurus) in the western North Atlantic. Marine and 929 Freshwater Research 66:158-169. DOI: 10.1071/MF14129.

930 Toonen RJ, Bowen BW, Iacchei M, Briggs JC. 2016. Biogeography, Marine. In: Kliman RM ed. 931 Encyclopedia of Evolutionary Biology. Oxford: Academic Press, 166-178. DOI: 10.1016/B978932 0-12-800049-6.00120-7.

933 Wenner EL, Knott DM, Van Dolah RF, Burrell VG. 1983. Invertebrate communities associated 934 with hard bottom habitats in the South Atlantic Bight. Estuarine, Coastal and Shelf Science 935 17:143-158. DOI: 10.1016/0272-7714(83)90059-8.

936 Wheaton C. 2018. Hardbottom characterization and relationship to the geologic framework in 937 Long Bay, South Carolina. Master of Science in Coastal Marine and Wetland Studies Thesis. 938 Conway, South Carolina: Coastal Carolina University.

939 Wootton JT. 1993. Indirect effects and habitat use in an intertidal community: Interaction chains 940 and interaction modifications. The American Naturalist 141:71-89. DOI: 10.1086/285461. 


\section{Figure 1}

Sand tiger sharks and round scad in association behaviors.

(A) No visible interaction (NVI). Image from 18 April 2017, 12:43 EDT, (B) Loosely associated (LA). Image from 11 November 2019, 16:05 EST, (C) Tightly associated (TA). Image from 13 March 2018, 14:14 EDT. Image credits: Erin Burge/Explore.org. 


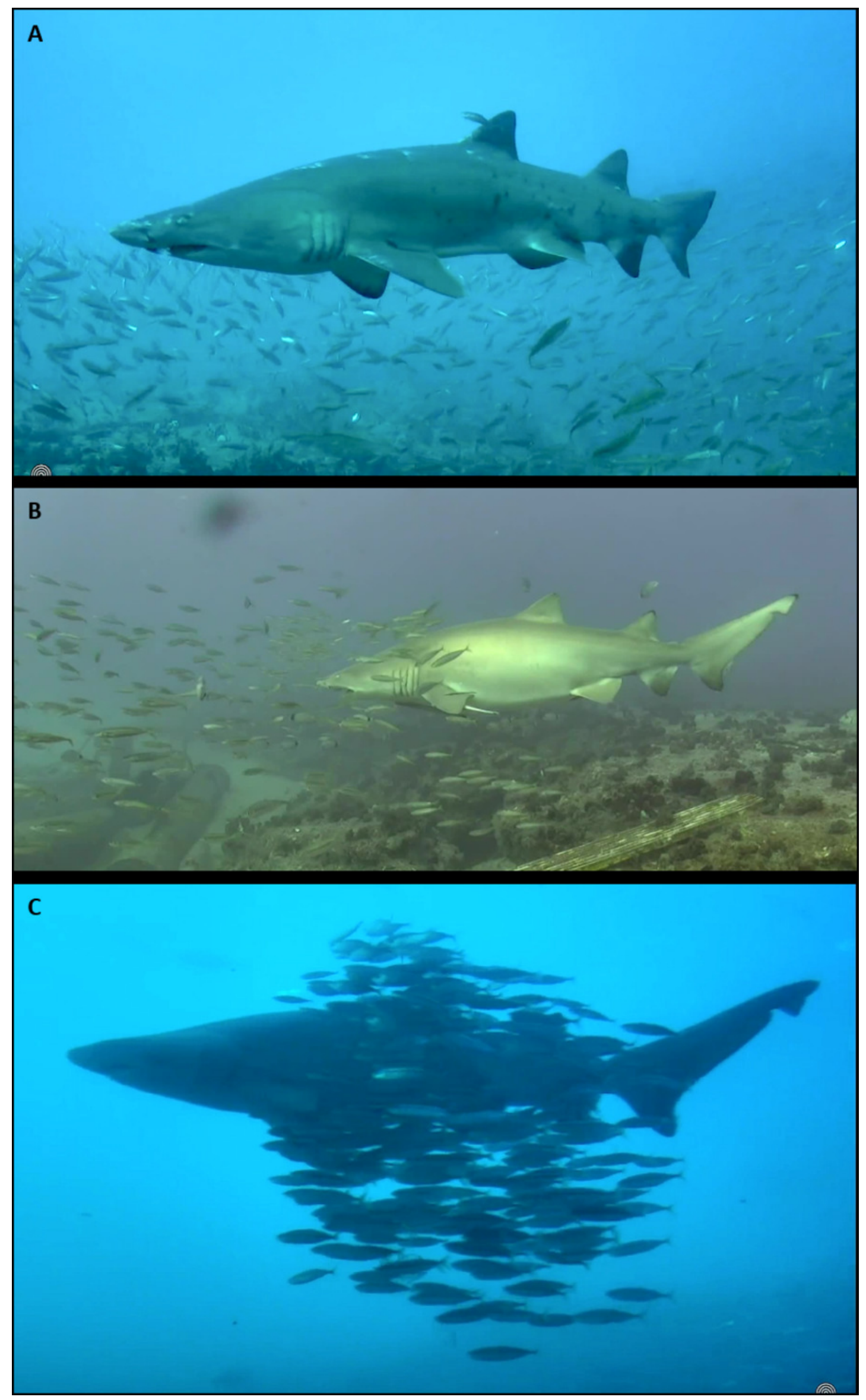

Peer) reviewing PDF | (2020:10:53884:1:2:NEW 28 Jan 2021) 


\section{Figure 2}

Association behavior between round scad (RS) and sand tiger sharks (STs) as a response to mesopredators (MPs).

Two sets of screen captures (A-D and E-H, lower left of each image) are representative of transitions between loose association (LA) and tight association (TA) that occur between RS and STs in the presence of MPs, little tunny (LT) and blue runner (BR). (A-D) RS are in LA with a STs. Two LT successively cause a rapid transition to TA. Once attacking mesopredators depart, RS transition to LA rapidly. View video at https://youtu.be/1Ss-AvAMkVg?t=180 (0:03:00). (E-H) RS are in LA with STs. A school of BR approaches and RS rapidly transition to TA behavior. View video at https://youtu.be/1Ss-AvAMkVg?t=925 (0:15:25). Video files are deposited in a public online repository on Zenodo (doi:10.5281/zenodo.4477423). Note that sandbar sharks (Carcharhinus plumbeus) are also present in some images. Image credits: Erin Burge/Explore.org. 




\section{Figure 3}

Association behavior and sand tiger shark predation.

Screen captures (A-D) are representative of tight association (TA) behavior between sand tiger sharks (STs1 and STs2) and round scad (RS). (A) Gag Mycteroperca microlepis, approaches, apparently not recognizing the presence of STs1. (B) Simultaneously, a little tunny (LT), approaches shrouded STs1 in what appears to be predation behavior on RS, disrupting the shroud. (C) The STs attempts to prey upon the gag, but (D) is unsuccessful. See the example video for additional information (https://youtu.be/cfGFAq1cQtl). Video files are deposited in a public online repository on Zenodo (doi:10.5281/zenodo.4477423). Image credits: Erin Burge/Explore.org.
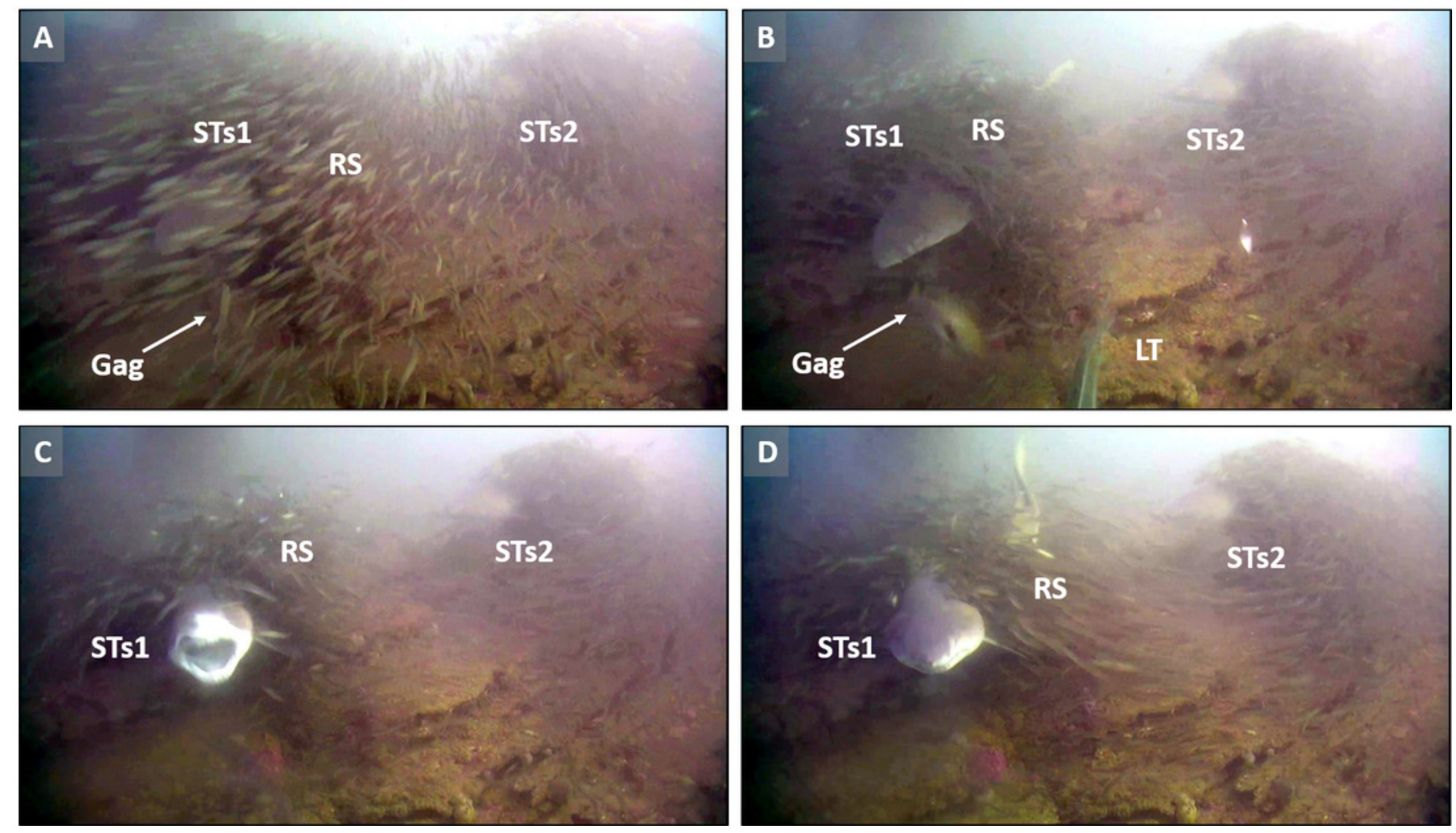


\section{Figure 4}

Frequency of occurrence of sand tiger sharks and round scad indicate the seasonality of their presence at Frying Pan Tower.

Seasonality of sand tiger sharks (STs) and round scad (RS) are represented by frequency of occurrence data (solid line, STs; dashed line, RS) from SharkCam videos ( $n=1024,20 \mathrm{~min}$ clips) from November 2014-January 2019. Video clips analyzed by month are indicated as $(n=)$. Sea surface temperatures (SST) are plotted as 2016 mean daily water temperature $\left({ }^{\circ} \mathrm{C}\right)$ \pm SD (open circles), 2003-2008 long term mean monthly SST (black circles on gray line), and 2003-2008 minimum and maximum monthly SST (gray stippled lines) at Frying Pan Tower (data from NOAA NBDC Station 41013 (LLNR 815)-Frying Pan Shoals, NC). 


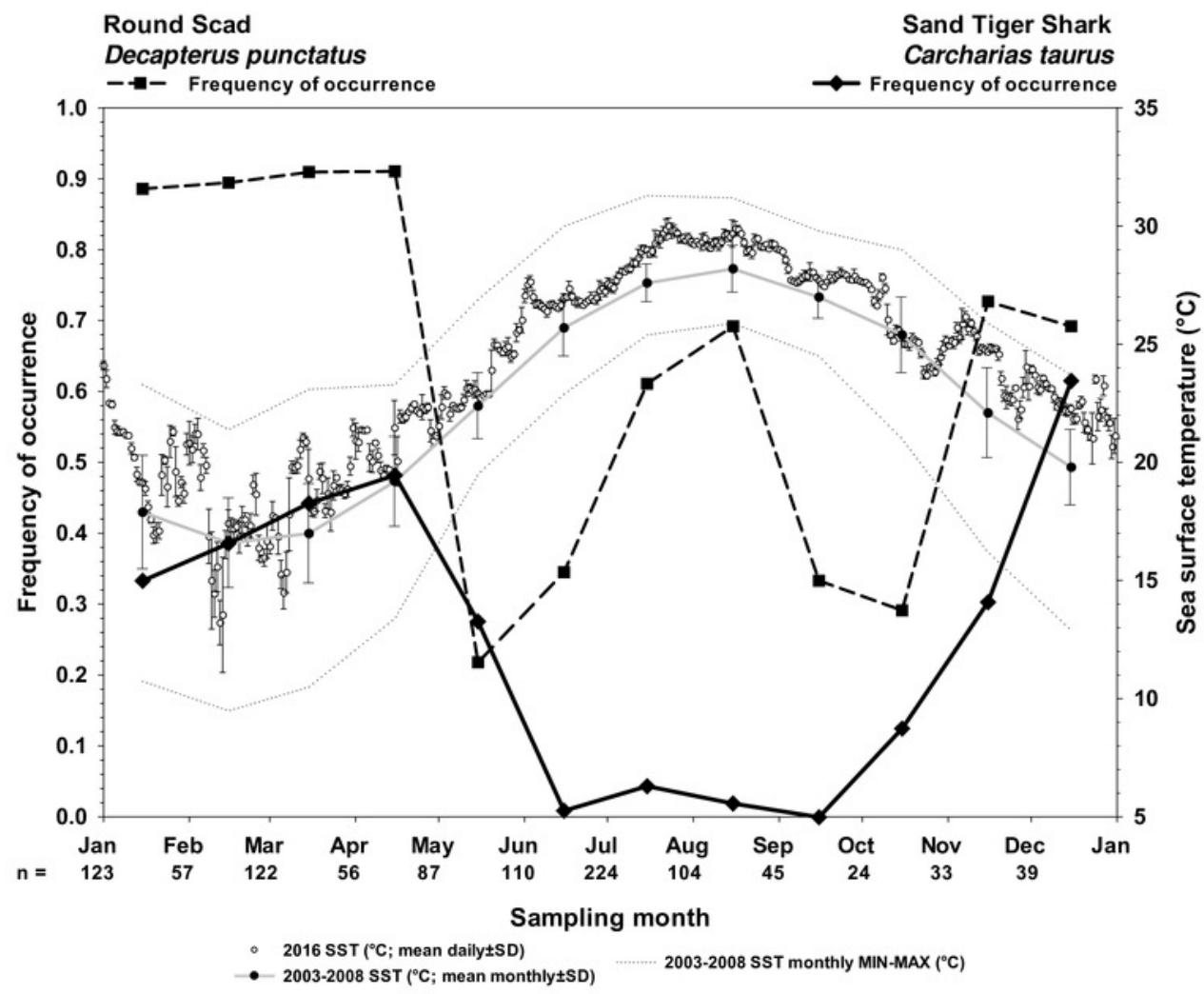


Figure 5

Cluster analysis of Bray-Curtis similarity to illustrate associations between sand tiger sharks (STs), round scad (RS), and individual mesopredator species (MPs).

See Table 1 for species acronyms. STs and RS cluster strongly (92.5\% similarity), while MPs have lower similarities. Clusters containing red-dashed branches are significant (Simprof, $\alpha=$ 0.05).

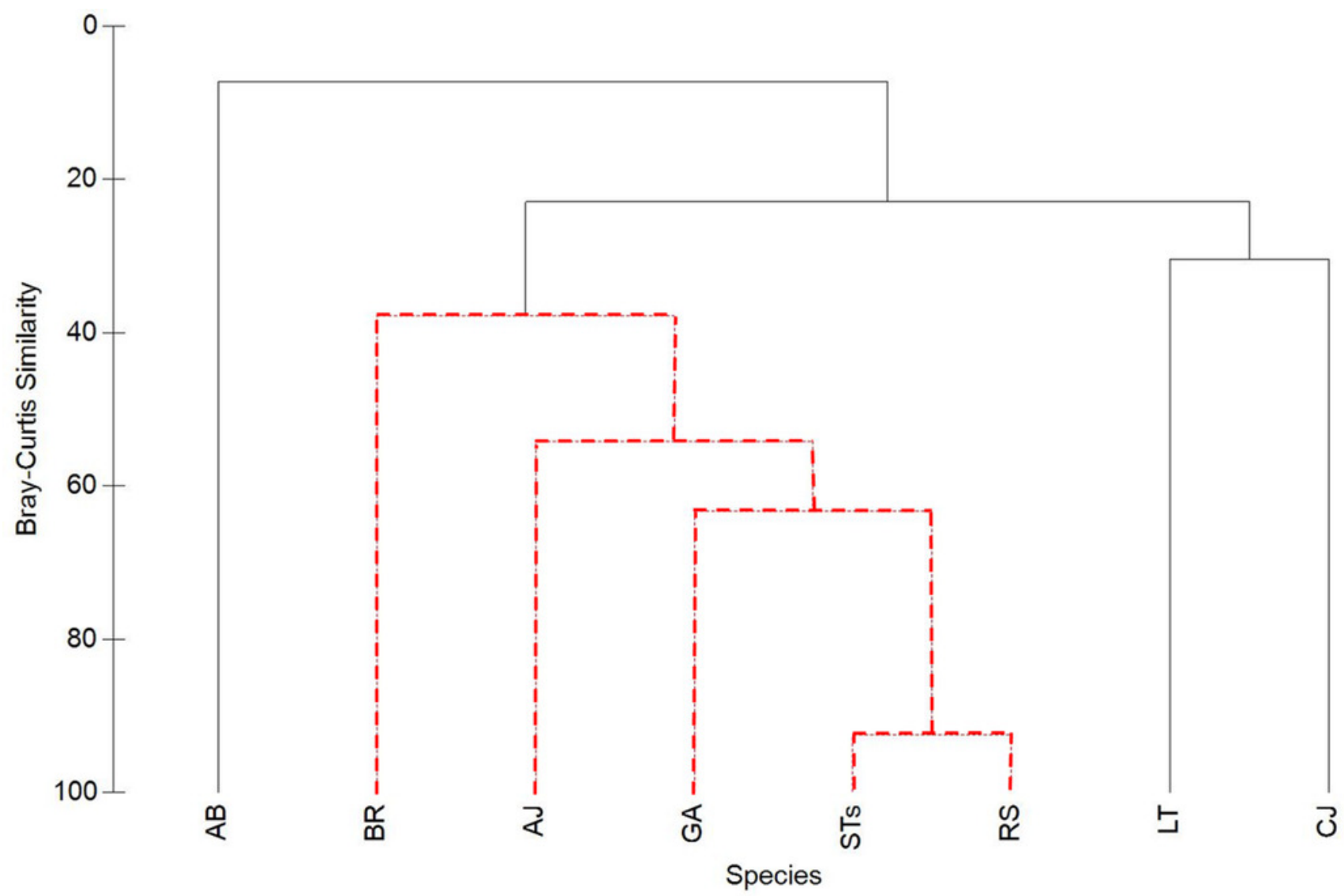




\section{Figure 6}

Association behavior counts between sand tiger sharks (STs) and round scad (RS).

(A) Without and with the presence of mesopredators (MPs), and observed and expected

frequencies (B) of association behaviors in video clips collected from SharkCam ( $n=186,20$ min clips). Tightly associated behavior between STs and RS occurred significantly more often than expected (Pearson's $\chi^{2}=20.981(\mathrm{df} 2), p<0.000$ ) in the presence of MPs. 


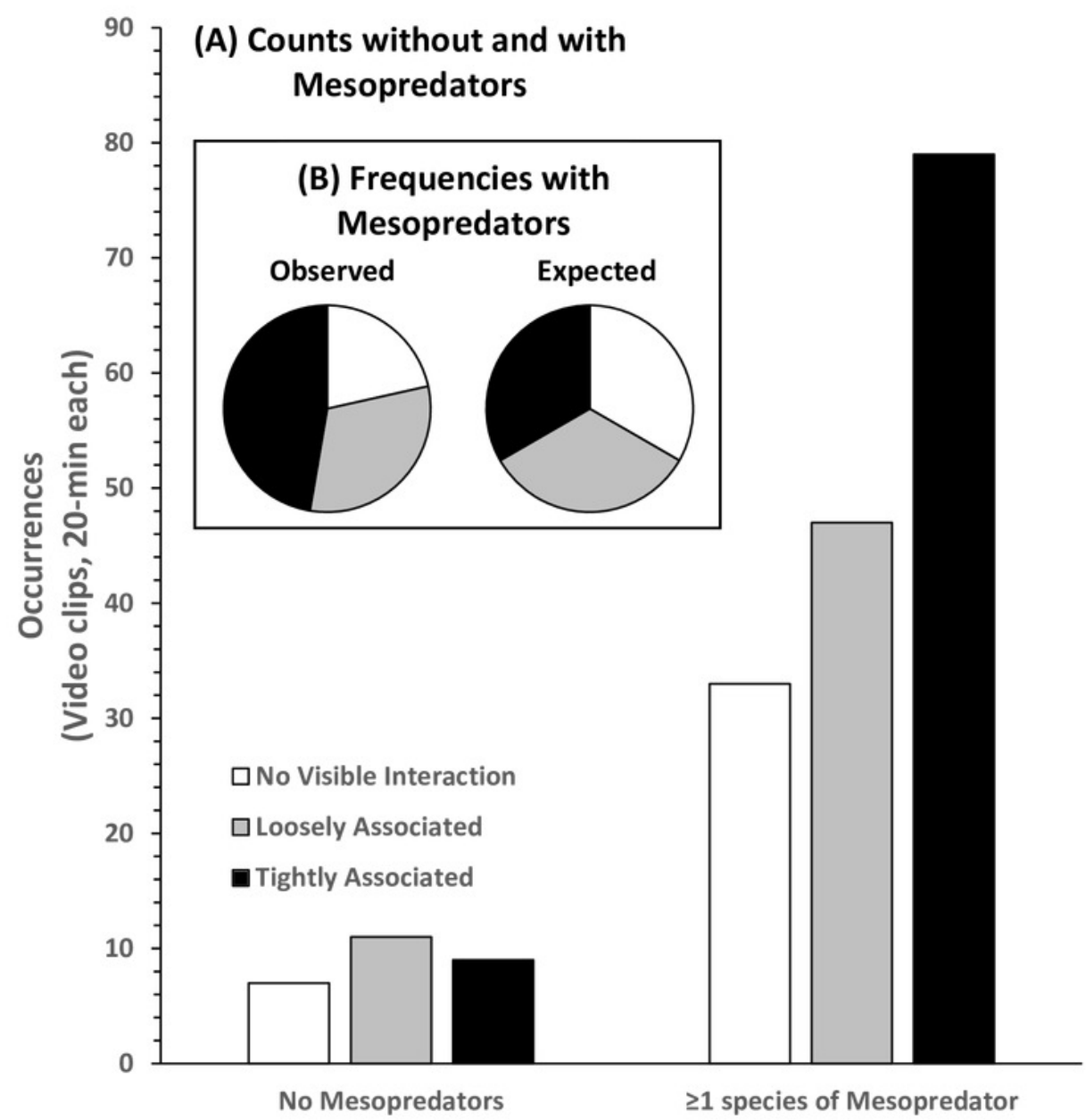




\section{Table $\mathbf{1}$ (on next page)}

Occurrence of sand tiger sharks, round scad, and six mesopredator species in SharkCam videos.

Videos analyzed ( $\mathrm{n}=1024,20$-min clips) were collected November 2014-January 2019.

Frequency of occurrence data are for all videos, and those known to contain STs ( $n=216,20$ min clips). The frequency of STs + RS in all clips was 0.138 . 


\begin{tabular}{|c|c|c|c|c|c|c|}
\hline \multirow[b]{2}{*}{ Common Name } & \multirow[b]{2}{*}{ Species } & \multirow[b]{2}{*}{ Acronym } & & \multirow[b]{2}{*}{ Videos containing } & \multicolumn{2}{|c|}{ Frequency of occurrence } \\
\hline & & & & & $\begin{array}{l}\text { In STs clips } \\
(\mathrm{n}=216)\end{array}$ & $\begin{array}{l}\text { In all clips } \\
(n=1024)\end{array}$ \\
\hline Sand Tiger Shark & Carcharias taurus & STs & \multirow{7}{*}{$\stackrel{\check{a}}{\Sigma}$} & 216 & 1.000 & 0.213 \\
\hline Round Scad & Decapterus punctatus & RS & & 186 & 0.861 & 0.648 \\
\hline Greater Amberjack & Seriola dumerili & $\mathrm{GA}$ & & 106 & 0.491 & 0.580 \\
\hline Almaco Jack & Seriola rivoliana & AJ & & 89 & 0.412 & 0.351 \\
\hline Blue Runner & Caranx crysos & BR & & 61 & 0.282 & 0.210 \\
\hline Crevalle Jack & Caranx hippos & CJ & & 25 & 0.116 & 0.164 \\
\hline Little Tunny & Euthynnus alletteratus & LT & & 34 & 0.157 & 0.078 \\
\hline \multirow[t]{2}{*}{ Atlantic Bonito } & Sarda sarda & $A B$ & & 9 & 0.042 & 0.015 \\
\hline & & & & $\begin{array}{l}\text { Frequency containing } \\
\mathrm{ST}+\mathrm{RS}+\geq 1 \mathrm{MPs}=\end{array}$ & 0.837 & 0.163 \\
\hline
\end{tabular}




\section{Table 2 (on next page)}

Attempted predation events by sand tiger sharks (STs) on mesopredators (MPs in bold) while in association with round scad (RS + STs).

All association behaviors were tightly associated (TA). Date (D Mmm YYYY) and time (U.S. Eastern Standard Time, UTC/GMT -5) are local to the camera. Video time refers to the time within the video clip of the attempt (H:MM:SS). Video files are deposited in a public online repository on Zenodo (doi:10.5281/zenodo.4477423). 


\begin{tabular}{|c|c|c|c|c|c|}
\hline Prey species & RS+STs & Date of occurrence & $\begin{array}{l}\text { Clock time of } \\
\text { occurrence }\end{array}$ & Video time & Video reference \\
\hline \multirow{2}{*}{ Little Tunny Euthynnus alletteratus } & TA & 19 Dec 2015 & 1121 EST & 0:00:08 & https://youtu.be/P37lg7iiDJo \\
\hline & TA & 06 Jan 2019 & 1040 EST & 0:00:09 & https://youtu.be/PIIHZr-ioeo \\
\hline Red Drum Sciaenops ocellatus & TA & $12 \operatorname{Jan} 2019$ & 1148 EST & $0: 19: 45$ & https://youtu.be/i5wO7ILbbd8 \\
\hline Blue Runner Caranx crysos & TA & $12 \operatorname{Jan} 2019$ & 1150 EST & $0: 20: 52$ & https://youtu.be/i5w07ILbbd8 \\
\hline Gag Mycteroperca microlepis & TA & $15 \operatorname{Jan} 2019$ & 0740 EST & 0:00:07 & https://youtu.be/cfGFAq1cQtl \\
\hline
\end{tabular}

